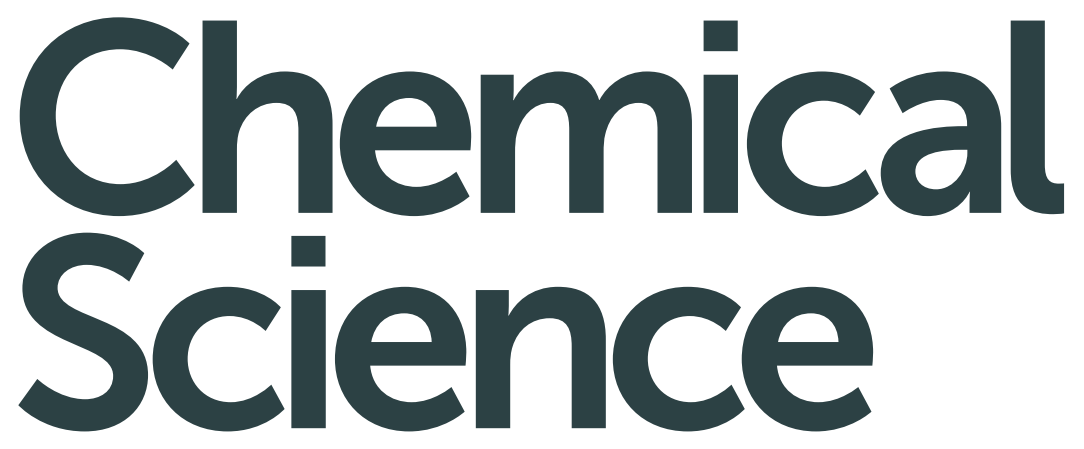

rsc.li/chemical-science

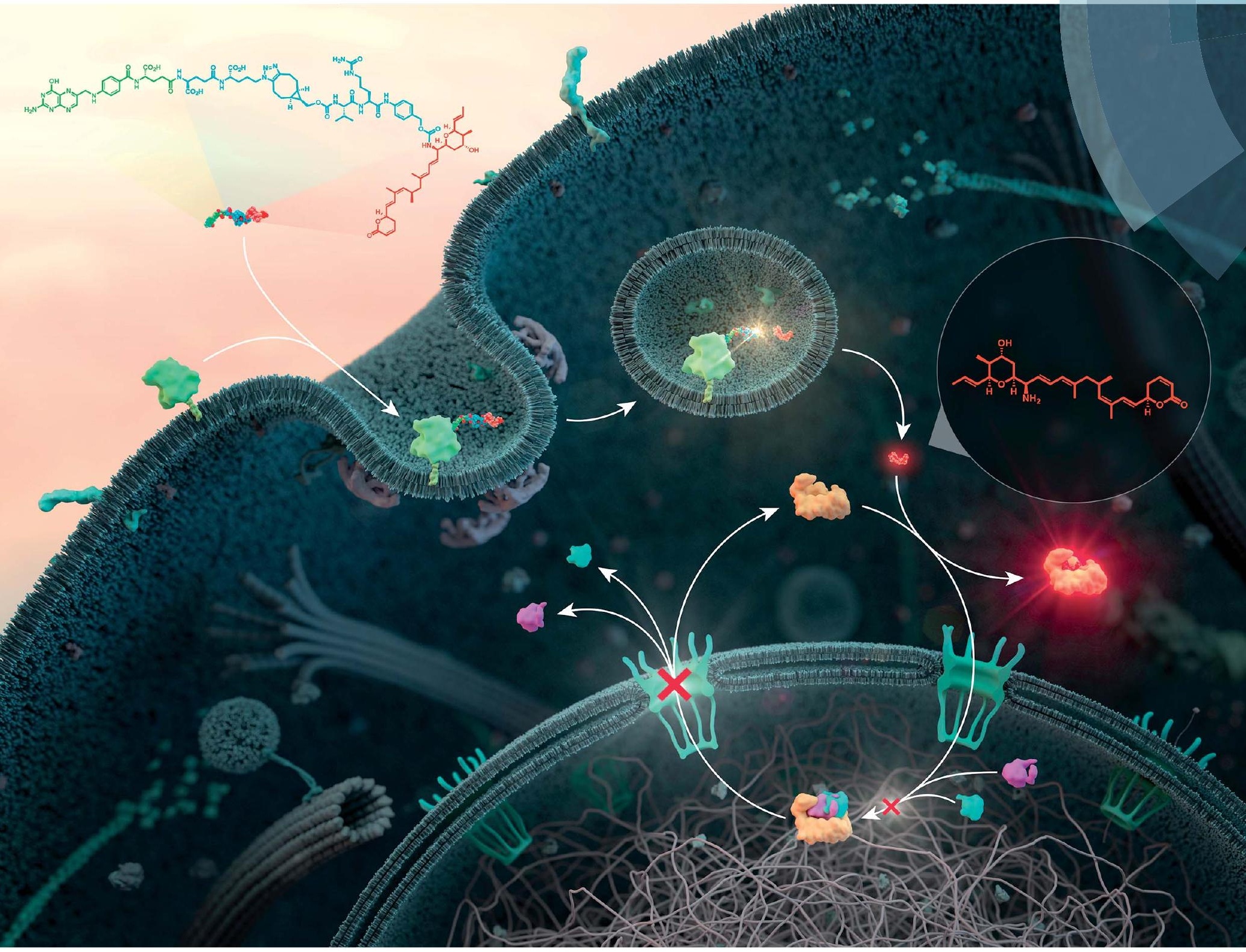

ISSN 2041-6539

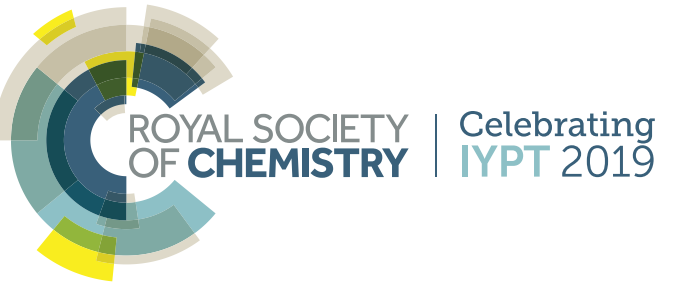

EDGE ARTICLE

Philipp Klahn, Mark Brönstrup et al.

The nuclear export inhibitor aminoratjadone is a potent

effector in extracellular-targeted drug conjugates

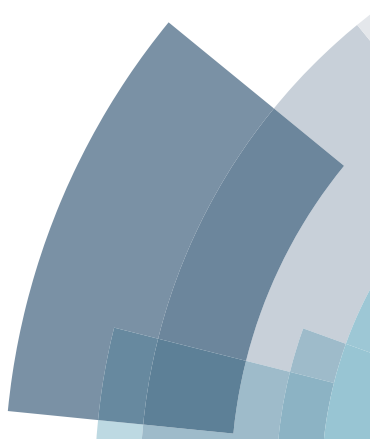


Check for updates

Cite this: Chem. Sci., 2019, 10, 5197

๑ All publication charges for this article have been paid for by the Royal Society of Chemistry

Received 11th December 2018

Accepted 15th April 2019

DOI: $10.1039 / \mathrm{c} 8 \mathrm{sc} 05542 \mathrm{~d}$

rsc.li/chemical-science

\section{The nuclear export inhibitor aminoratjadone is a potent effector in extracellular-targeted drug conjugates $\dagger$}

\author{
Philipp Klahn, (D) *ac Verena Fetz, ${ }^{a}$ Antje Ritter, ${ }^{a}$ Wera Collisi, ${ }^{\text {ab }}$ Bettina Hinkelmann, ${ }^{a}$ \\ Tatjana Arnold, ${ }^{a}$ Werner Tegge, ${ }^{a}$ Katharina Rox, ${ }^{\text {af }}$ Stephan Hüttel, (iD b Kathrin I. Mohr, ${ }^{\text {b }}$ \\ Joachim Wink, ${ }^{b}$ Marc Stadler, (iD b Josef Wissing, ${ }^{\text {d }}$ Lothar Jänsch $^{d}$ \\ and Mark Brönstrup (D) *aef
}

The concept of targeted drug conjugates has been successfully translated to clinical practice in oncology. Whereas the majority of cytotoxic effectors in drug conjugates are directed against either DNA or tubulin, our study aimed to validate nuclear export inhibition as a novel effector principle in drug conjugates. For this purpose, a semisynthetic route starting from the natural product ratjadone $A$, a potent nuclear export inhibitor, has been developed. The biological evaluation of ratjadones functionalized at the 16-position revealed that oxo- and amino-analogues had very high potencies against cancer cell lines (e.g. 16Raminoratjadone 16 with $I C_{50}=260$ pM against MCF-7 cells, or 19-oxoratjadone 14 with $I C_{50}=100$ pM against A-549 cells). Mechanistically, the conjugates retained a nuclear export inhibitory activity through binding CRM1. To demonstrate a proof-of-principle for cellular targeting, folate- and luteinizing hormone releasing hormone (LHRH)-based carrier molecules were synthesized and coupled to aminoratjadones as well as fluorescein for cellular efficacy and imaging studies, respectively. The TrojanHorse conjugates selectively addressed receptor-positive cell lines and were highly potent inhibitors of their proliferation. For example, the folate conjugate FA-7-Val-Cit-pABA-16R-aminoratjadone had an $\mathrm{IC}_{50}$ of $34.3 \mathrm{nM}$, and the LHRH conjugate D-Orn-Gose-Val-Cit-pABA-16R-aminoratjadone had an IC 50 of $12.8 \mathrm{nM}$. The results demonstrate that nuclear export inhibition is a promising mode-of-action for extracellular-targeted drug conjugate payloads.

\section{Introduction}

Extracellular-targeted drug conjugates (EDCs) have recently evolved into an innovative, clinically proven molecular format in tumor therapies. ${ }^{1-11}$ The linkage of potent cytotoxins to appropriate carrier molecules, ligands with a high affinity for

${ }^{a}$ Department of Chemical Biology, Helmholtz Centre for Infection Research, Inhoffenstrasse 7, 38124 Braunschweig, Germany. E-mail: mark.broenstrup@ helmholtz-hzi.de

${ }^{b}$ Department of Microbial Drugs, Helmholtz Centre for Infection Research, Inhoffenstrasse 7, 38124 Braunschweig, Germany

'Institute of Organic Chemistry, Technische Universität Braunschweig, Hagenring 30, 38106 Braunschweig, Germany. E-mail: p.klahn@tu-braunschweig.de

${ }^{d}$ Department of Structure and Function of Proteins, Research Group Cellular Proteomic, Helmholtz Centre for Infection Research, Inhoffenstrasse 7, 38124 Braunschweig, Germany

eBiomolecular Drug Research Center (BMWZ), Schneiderberg 38, 30167 Hannover, Germany

${ }^{f}$ German Centre of Infection Research (DZIF), Partner Site Hannover-Braunschweig, Germany

$\dagger$ Electronic supplementary information (ESI) available. See DOI: $10.1039 / \mathrm{c} 8 \mathrm{sc} 05542 \mathrm{~d}$ a cancer-specific biomarker overexpressed on the surface of malignant cells, enables the selective delivery of the cytotoxins to the cancer cells. After endocytosis-mediated uptake of such conjugates, the cytotoxins drive the cell into apoptosis. Compared to conventional chemotherapeutics, EDCs exhibit a broadened therapeutic window, since the exposure of healthy cells to the highly potent cytotoxins is significantly reduced. Most advances have been achieved so far utilizing antibodies as carrier molecules, as three antibody-drug conjugates (ADCs) have obtained marketing authorization, i.e. Adcetris ${ }^{\circledR}$ (2011), Kadcyla ${ }^{\circledR}$ (2011), and Besponsa ${ }^{\circledR}$ (2017), and about 60 further ADC candidates are in clinical trials. ${ }^{9}$ In addition, several other types of biomolecular carriers like probodies ${ }^{12}$ or anticalins, ${ }^{13-15}$ and small molecule carriers like vitamins ${ }^{16}$ such as folic acid, ${ }^{17-20}$ peptide hormone derivatives such as octreotide ${ }^{21-24}$ and LHRH $^{25-29}$ and integrin binding RGD- and isoDGR peptides $^{30}$ are under preclinical and clinical investigation as part of EDCs. Folic acid (vitamin $\mathrm{B}_{9}$ ) is a crucial growth factor for all cell types, ${ }^{19,31}$ because it is a cofactor in C1-transfer reactions especially in the synthesis of DNA and RNA bases. ${ }^{31}$ Several cancer cell types overexpress specific receptors (mainly folate receptor- $\alpha, \mathrm{FR} \alpha)$ that have a high folate affinity $(<1 \mathrm{nM})$ 
and mediate its uptake via endocytosis. ${ }^{31}$ Folate-fluorophore conjugates have already been successfully applied for diagnostic cancer imaging ${ }^{31,32}$ and for intraoperative fluorescence imaging during tumor surgery. ${ }^{31,33,34}$ Furthermore, folate-drug conjugates have been demonstrated to selectively deliver cytotoxins to cancer cells. ${ }^{17,31}$

Remarkably, the cytotoxic payloads in approved ADCs as well as in most preclinical and clinical EDCs are all derived from natural products. The far majority of them falls into only two modes of action categories: (1) antimitotic, microtubule binding agents (e.g. tubulysines, auristatins, maytansinoids, taxols, epothilones, vincristines etc.), ${ }^{35-41}$ (2) agents causing DNA damage by alkylation or intercalation (calicheamycins, duocarmycins, PBD's, or anthracyclines). ${ }^{36,37,39,42}$ In addition, few other mechanisms, including RNA polymerase inhibition by $\alpha$-aminitin ${ }^{43}$ and spliceosome targeting by e.g. thailanstatin $\mathrm{A},{ }^{44}$ have been studied as EDCs. ${ }^{37}$ Considering the high incidence of cancer relapse or development of metastasis after seemingly successful chemotherapeutic treatment, ${ }^{\mathbf{4 5 - 4 8}}$ and the ability of tumors to become multi-drug resistant, ${ }^{\mathbf{4 9 , 5 0}}$ there is a strong need to investigate new cytotoxic payloads for EDCs with different modes of action to enable more stratified tumor treatments in the future. In this context we got interested in (+)-ratjadone A (1) and related analogs (Fig. 1), polyketidic natural products produced by the myxobacterium Sorangium
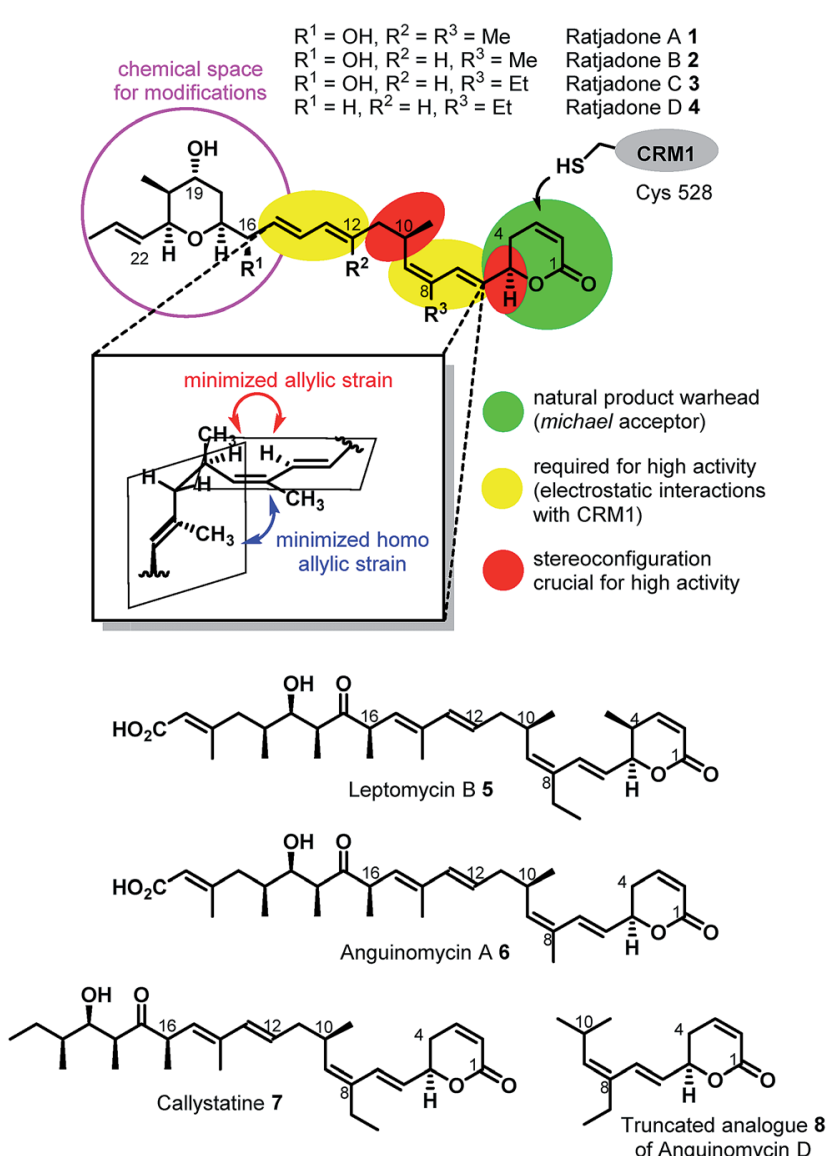

Fig. 1 Structures and SAR of ratjadones $A-D$ and related CRM1 inhibitors. cellulosum..$^{51,52}$ Ratjadones, structurally related to leptomycins, ${ }^{53}$ show potent, sub-nanomolar antiproliferative activity against several cancer cell lines including multi-drug-resistant ones. ${ }^{\mathbf{5 4}}$ The antiproliferative activity of ratjadones is based on the inhibition of CRM1, ${ }^{54,55}$ a protein receptor involved in the nuclear export of substrates larger than $40 \mathrm{kDa}$ from the nucleus into the cytosol of mammalian cells. ${ }^{56,57}$ Since the inactivation of CRM1 leads to inhibition of central cellular functions, ${ }^{58}$ reduction of angiogenesis and metastatic ability of tumors, ${ }^{59}$ sensitization of the cancer cell to other drugs ${ }^{59-61}$ and finally to cell death, the inhibition of nuclear export mediated by CRM1 is regarded as an attractive anticancer mechanism. However, early clinical trials with the CRM1-inhibitor leptomycin B as a standalone drug failed due to its high systemic toxicity. ${ }^{62}$

For these reasons, we aimed to establish extracellulartargeted conjugates based on highly potent CRM1 inhibitors in order to explore nuclear export as an anticancer strategy. We describe a semisynthetic approach to novel ratjadone A analogues bearing amino moieties for an easy and selective conjugation and their biological evaluation, thereby establishing structure-activity relationships. Furthermore, we report the synthesis of novel folate- and luteinizing hormone releasing hormone (LHRH)-based carrier molecules, their conjugation with aminoratjadone-payloads and their biological evaluation, which led to the discovery of novel EDCs with an antiproliferative activity in the low double-digit nanomolar range.

\section{Result and discussion}

\section{Derivatization of (+)-ratjadone $A$}

The first total synthesis of (+)-ratjadone A (1) was published in 2001 by Kalesse and coworkers ${ }^{63}$ and utilized for the synthesis of several derivatives. ${ }^{64-66}$ However, in order to assure an economic, scalable access to gram amounts of the natural product as required for the development of EDCs, we established a reliable fermentation protocol with an optimized strain of the myxobacterial producer Sorangium cellulosum (Soce1047). Fermentation titers of up to $32 \mathrm{mg} \mathrm{L}^{-1}$ of 1 were obtained after 3-7 days, and an optimized downstream process led to an isolated total amount of $3.646 \mathrm{~g}$ of 1 within a few weeks from $150 \mathrm{~L}$ of culture (see ESI $\dagger$ ). To retain the potent antiproliferative activity of 1 during semisynthetic derivatization, several parts of the molecule need to remain unchanged. Its warhead is a $\alpha, \beta$ unsaturated $\delta$-lactone (Fig. 2), which serves as a Michael acceptor and covalently binds to the cysteine 528 of the target protein CRM1, resulting in lacton hydrolysis and irreversible inhibition of CRM1. ${ }^{55}$ Furthermore, structure-activity relationship studies of simplified analogues and stereoisomers of 1 revealed that the absolute stereo configuration at C5 and C10 as well as the two diene moieties are crucial for a high antiproliferative activity, since the minimization of the allylic and homo allylic strain defines the overall shape of the natural product. ${ }^{64}$ These structural features are shared with other potent CRM1 inhibitors such as leptomycin B (5) (Fig. 1), anguinomycin A (6) and callistatin A (7), and their importance has been rationalized by co-crystal structures. ${ }^{53,55}$ In 2010 
A

B
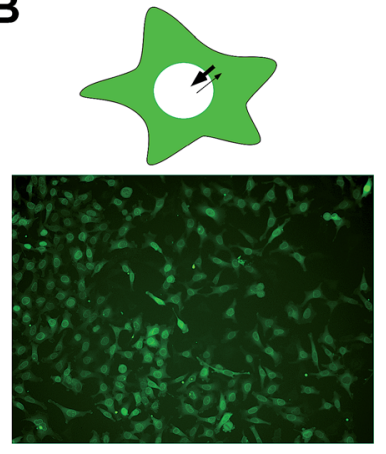

DMSO control

C

\begin{tabular}{cc}
\hline & $\begin{array}{c}\text { nuclear } \\
\text { export } \\
\text { inhibition } \\
\text { IC } 50 \text { [nM] }\end{array}$ \\
\hline $\mathbf{1}$ & 1.2 \\
$\mathbf{1 3}$ & 52.5 \\
$\mathbf{1 4}$ & 13.3 \\
$\mathbf{1 5}$ & 17.5 \\
$\mathbf{1 6}$ & 2.7 \\
$\mathbf{1 7}$ & 2.8 \\
$\mathbf{2 0}$ & 23.2 \\
$\mathbf{2 1}$ & 46.1 \\
$\mathbf{2 2}$ & 12.0 \\
$\mathbf{2 5}$ & 246 \\
$\mathbf{3 3}$ & 70.0 \\
$\mathbf{3 6}$ & 18.3 \\
$\mathbf{3 6}$ & 152 \\
\hline
\end{tabular}
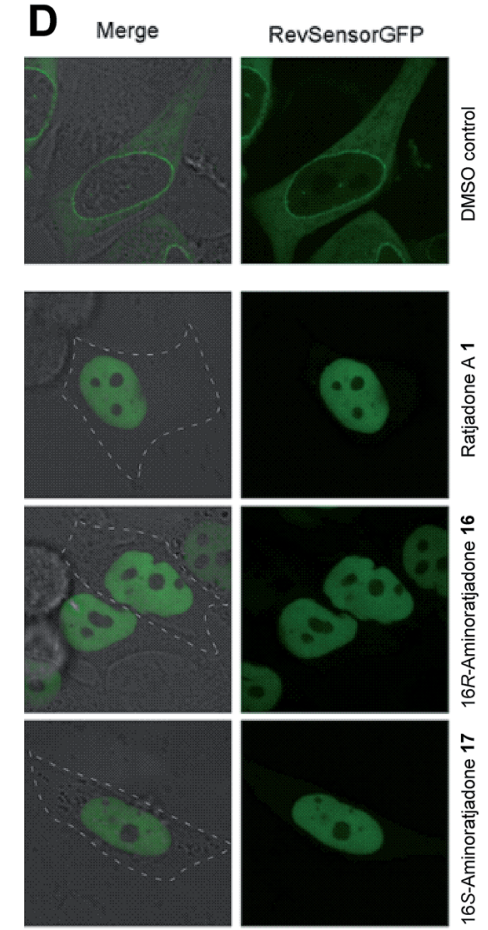

Fig. 2 Inhibition of nuclear export by ratjadone A derivatives in recombinant HeLa cells. (A) Functional domains in fluorescent translocation biosensor system. (B) Cellular distribution of biosensor in untreated (left) and ratjadone $A$ treated HeLa cells (right). (C) $I C_{50}$ values of nuclear export inhibitory activity. (D) Fluorescence microscopy pictures of biosensor expressing HeLa cells treated with 1, 16, and 17 .

Gademann and coworkers demonstrated that the truncated analogue 8 of anguinomycin D (Fig. 1), missing one of the diene moieties, inhibits nuclear export at concentration of $25 \mathrm{nM}^{67,68}$ However, sub-nanomolar activities require both diene moieties.

Our derivatization approaches therefore focused on modifications in the pyrane core and the adjacent allylic hydroxy group. Because an acylation of the two hydroxy groups proceeded with low yields and hardly showed any selectivity, ${ }^{54}$ we planned to introduce an amino handle to the molecule to enable selective conjugations with carrier molecules. In a first derivatization strategy (Scheme 1), a selective silylation of the C16 hydroxy function in the presence of 2.3 equivalents of
TBSOTf at $-100{ }^{\circ} \mathrm{C}$ for $3 \mathrm{~h}$ gave compound 9 in $62 \%$ yield based on recovered starting material (brsm) together with some double TBS-protected material. We assume that the limited yield was a consequence of the low nucleophlic reactivity of the hydroxyl groups.

As TBSCl was completely unreactive, the relatively strong Lewis acid TBSOTf had to be applied for the silylation, which led at least to some decomposition of the natural product. Compound 9 could be further converted into the corresponding C19 O-mesylate 10 in 98\% yield.

However, the envisaged nucleophilic substitution with sodium azide did not proceed at ambient temperatures and led to slow decomposition of the starting material without any formation of substitution product at higher temperatures. An alternative Mitsunobu reaction in the presence of diphenylphosphoryl azide showed no conversion at reaction temperatures up to $40{ }^{\circ} \mathrm{C}$, while higher reaction temperature led to slow decomposition of the starting material.

Additionally, attempts to selectively oxidize with ozone, dihydroxylate or epoxidize the double bound between C22 and C23 of 1 were unsuccessful and led to non-selective reactions or decomposition of the natural compound. In a second derivatization strategy (Scheme 2) we envisaged a selective oxidation of the more reactive allylic alcohol at $\mathrm{C} 16$, followed by a reductive amination. While no oxidation of $\mathbf{1}$ was observed in the presence of $\mathrm{MnO}_{2}$ (the compound was quantitatively reisolated after $24 \mathrm{~h}$ at $50{ }^{\circ} \mathrm{C}$ ), the use of PCC in methylene dichloride led to fast decomposition. A first success was achieved using Dess-Martin periodinane (DMP) in methylene chloride, yielding the desired 16-oxoratjadone 13 (Scheme 2) in 63\% brsm. Improved yields were obtained by dropping a solution of 1.1 equiv. of freshly prepared iodoxybenzoic acid (IBX) ${ }^{69}$ in dimethyl sulfoxide into a diluted solution of $\mathbf{1}$ over a period of $16 \mathrm{~h}$, giving the 16-oxoratjadone 13 together with the 19-oxoratjadone 14 and the 16,19dioxoratjadone 15 in $75 \%, 15 \%$ and $8 \%$ yields (all brsm) after chromatographic separation, respectively. Higher amounts of IBX or faster addition of the oxidant led to predominant formation of diketone 15. Finally, a reductive amination of $\mathbf{1 3}$ in the presence of an excess of ammonium acetate and sodium cyanoborohydride at $23{ }^{\circ} \mathrm{C}$ gave $16 R$-aminoratjadone 16 and $16 S$-aminoratjadone 17 in $32 \%$ brms and $21 \%$ brsm, respectively, together with small amounts of the compounds 18 and 19, in which the dihydropyran-2-one warhead was destroyed. All displayed a significantly increased water solubility compared to $\mathbf{1}$. Milder reaction conditions at $0{ }^{\circ} \mathrm{C}$ resulted in significantly longer reactions times, uncomplete conversion and predominant formation of 18 and 19 (Scheme 2), whereas the use of sodium trimethoxy borohydride led to no conversion at all. The absolute stereo configuration at the C16 position was determined by Mosher's method based on the corresponding Mosher amides of 16 and $17^{70-72}$ We then functionalized 16 or 17 with noncleavable as well as enzymatically cleavable linker moieties at the C16 amino function. The derivatives 20, 21 and 22 (Scheme 3), bearing amide- and carbamate-linked short terminal alkyne moieties as attachment points for appropriate carrier molecules, could be generated by reaction with the $N$-hydroxysuccinimide ester $\mathbf{2 3}$ or the $p$-nitrophenyl carbonate $\mathbf{2 4}$. The aminoratjadone 


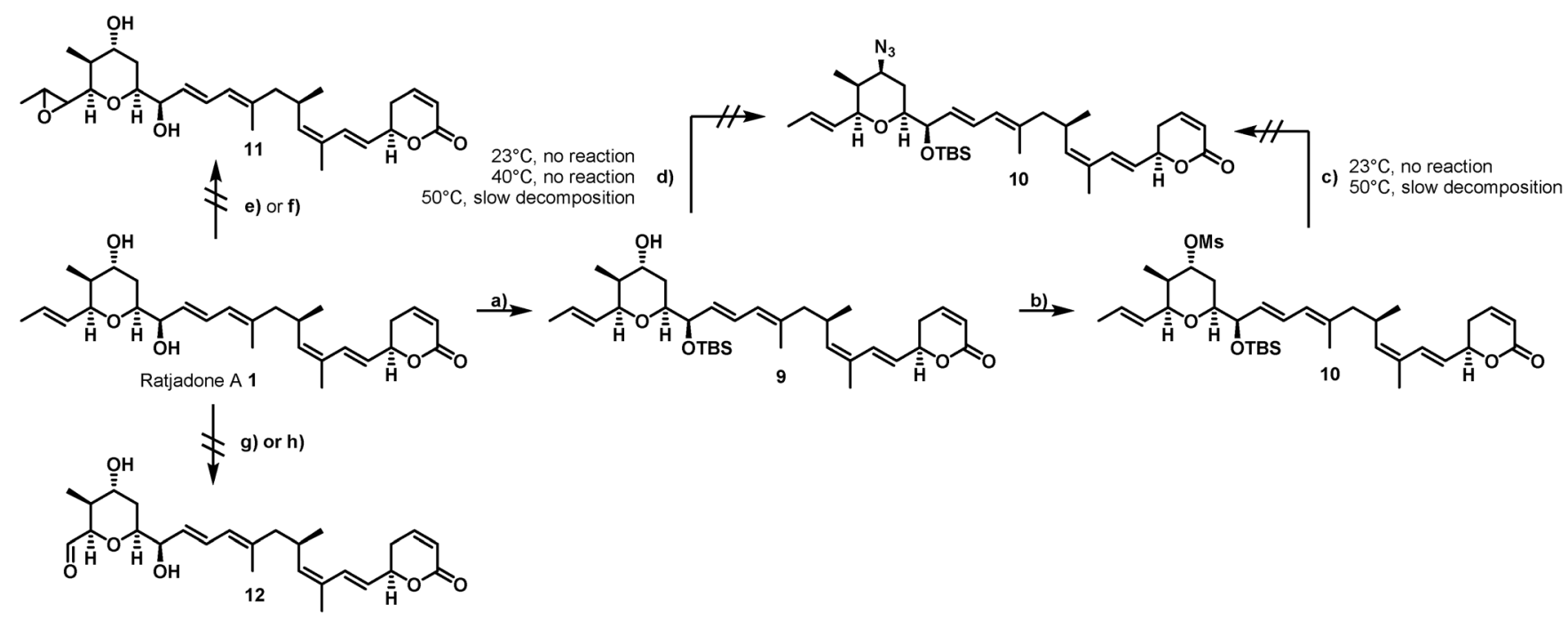

Scheme 1 Unsuccessful strategies for the selective derivatization of ratjadone A. Reagents and conditions: (a) TBSOTf (2.3 equiv.), 2,6-lutidine (2.6 equiv.), $\left(\mathrm{CH}_{2} \mathrm{Cl}_{2}\right),-100{ }^{\circ} \mathrm{C}, 3 \mathrm{~h}, 62 \%$ brsm; (b) $\mathrm{MsCl}$ (3.3 equiv.), Py (4.0 equiv.), $\left(\mathrm{CH}_{2} \mathrm{Cl}_{2}\right), 23{ }^{\circ} \mathrm{C}, 3.5 \mathrm{~h}, 98 \%$; (c) $\mathrm{NaN}$ ( 3.0 equiv.), (DMF); (d) $\operatorname{DIAD}$ (1.1 equiv.), $\mathrm{PPh}_{3}$ (1.15 equiv.), DPPA (1.0 equiv.), (THF); (e) $m \mathrm{CPBA}\left(1.0\right.$ equiv., $\mathrm{NaHCO}_{3}\left(1.05\right.$ equiv.), $\left(\mathrm{CH}_{2} \mathrm{Cl}_{2}: \mathrm{H}_{2} \mathrm{O} / 3: 1\right), 0{ }^{\circ} \mathrm{C}$ or $-10{ }^{\circ} \mathrm{C} ;(\mathrm{f})$ DMDO (1.1 equiv.), $\left(\mathrm{CH}_{2} \mathrm{Cl}_{2}\right),-30^{\circ} \mathrm{C} ;$ (g) $\mathrm{O}_{3},\left(\mathrm{CH}_{2} \mathrm{Cl}_{2}: \mathrm{MeOH} / 9: 1\right),-78^{\circ} \mathrm{C}, \mathrm{PPh}_{3}$ (xs); (h) $\mathrm{OsO}_{4}(0.01$ equiv.), $\mathrm{NMO}$ (1.0 equiv.) or PNO (1.0 equiv.), $\left(\mathrm{CH}_{2} \mathrm{Cl}_{2}\right), 0{ }^{\circ} \mathrm{C}$ or $-10{ }^{\circ} \mathrm{C}$.
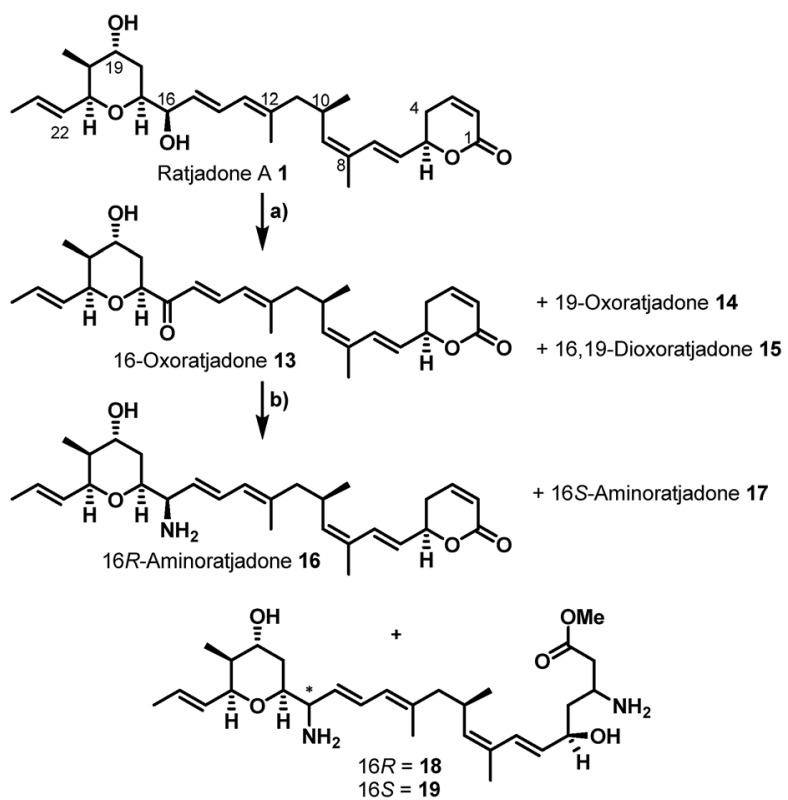

Scheme 2 Semi-synthesis of C16-aminoratjadones from (+)-ratjadone A. Reagents and conditions: (a) IBX (1.1 equiv.), (DMSO, 0.075 M), $23{ }^{\circ} \mathrm{C}$. Addition of $16 \mathrm{~h}+23^{\circ} \mathrm{C}$. $24 \mathrm{~h}, 75 \%$ brms $13,8 \%$ brms $14,15 \%$ brms 15. (b) $\left(\mathrm{NH}_{4}\right) \mathrm{OAc}\left(10\right.$ equiv.), $\mathrm{NaCNBH}_{3}$ (2.0 equiv.), (MeOH), $23{ }^{\circ} \mathrm{C}, 13 \mathrm{~h}+40{ }^{\circ} \mathrm{C}, 2 \mathrm{~h}, 34 \%$ brsm $16,21 \%$ brms $17,8 \%$ brsm $18,2 \%$ brsm 19 .

derivatives 25 and 26 (Scheme 3) carried a valine-citrulline-pABA unit that can be cleaved intracellularly by the lysosomal enzyme cathepsin $\mathrm{B}^{73-76}$ They were obtained by reaction of 16 with $p$ nitrophenyl carbonates $\mathbf{2 7}$ or $\mathbf{2 8}$, respectively (for synthesis of $\mathbf{2 7}$ and 28 see ESI $\dagger$ ).

Furthermore, 29 and 30, bearing disulfide bridges that are supposed to be reductively cleaved in the cell, were obtained from 16 by amide formation in the presence of $\mathbf{3 0}$ (for synthesis of 30 see ESI $\dagger$ ) and stoichiometric amounts of TSTU, or by conversion with the commercially available $\mathrm{N}$-succinimidyl 3-(2pyridyldithio)-propionate 32 . In parallel, we used the byproduct 19-oxoratjadone $\mathbf{1 4}$ for the synthesis of further C19aminoratjadone derivatives (Scheme 4).

The direct reductive amination of $\mathbf{1 4}$ in the presence of ammonium acetate and sodium cyanoborohydride gave 19aminoratjadone 33 as an inseparable $2: 1$-mixture of both diastereomers, which could be further converted to $\mathbf{3 4}$ in the presence of $p$-nitrophenyl carbonate 24 , or to 35 in the presence of propargylamine.

\section{Biological evaluation of novel aminoratjadones and derivatives}

All ratjadone A derivatives were biologically evaluated for their antiproliferative activity against a panel of cancer cell lines representing human cervix, ovarian, breast and lung carcinomas. While the 16-oxoratjadone 13 and the 16,19-dioxoratjadone 15 showed slightly decreased antiproliferative activity compared to $\mathbf{1}$, which could be rationalized by the electronic influence of the 16-oxo function to the second diene system, 19-oxoratjadone 14 was equally active. Fortunately, also $16 R$-aminoratjadone 16 displayed strong antiproliferative activity, equipotent with the natural template. However, the activity of $16 S$-analog 17 was fourfold decreased compared to 16 with the $16 R$-configuration. A significant drop in activity was observed for 18 and 19 bearing a ring-opened warhead, although the compounds are still highly active in absolute terms, with $\mathrm{IC}_{50}$ values of $115.6 \mathrm{nM}$ and $165.4 \mathrm{nM}$, respectively. We speculate that the derivatives might still serve as noncovalent inhibitors of CRM1. Alternatively, an elimination of the $\beta$-amino group under assay conditions at C3 would lead to 

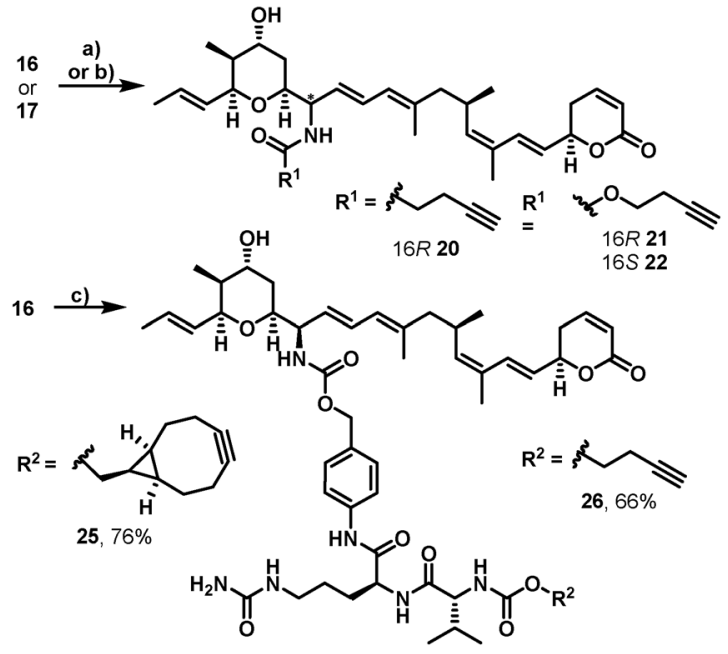<smiles>C#CCCC(=O)NCCSSCCC(=O)N[C@H](/C=C/C=C(\C)CC(C)/C=C(C)/C=C/[C@@H]1CC=CC(=O)O1)[C@@H]1C[C@H](O)[C@@H](C)[C@H](/C=C/C)O1</smiles><smiles>C/C=C/[C@H]1O[C@H](C(/C=C/C=C(\C)CC(C)/C=C(C)/C=C/[C@H]2CC=CC(=O)O2)NC(=O)CCSSc2ccccn2)C[C@@H](O)C1C</smiles>

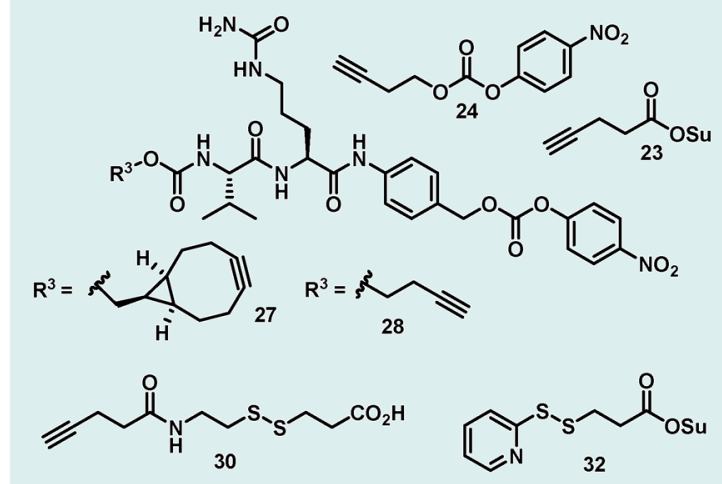

Scheme 3 Synthesis of $\mathrm{C} 16$-aminoratjadones bearing short terminal alkyne moieties and enzymatically cleavable Val-Cit-pABA or disulphide linkers. Reagents and conditions: (a) 22 (1.1 equiv.), NMM (3.0 equiv.), $\left(\mathrm{CH}_{2} \mathrm{Cl}_{2}\right) .23^{\circ} \mathrm{C}, 1.5 \mathrm{~h}, 65 \%$ for 20 ; (b) 24 (1.1 equiv.), NMM (3.0 equiv.), $\left(\mathrm{CH}_{2} \mathrm{Cl}_{2}\right), 23{ }^{\circ} \mathrm{C}, 20 \mathrm{~h} ; 90 \%$ for 21 and $69 \%$ for 22 ; (c) 27 or 28 (1.1 equiv.), NMM (6.0 equiv.), (DMF), $23^{\circ} \mathrm{C} .26 \mathrm{~h}, 76 \%$ for 25 and $66 \%$ for 26; (d) 30 (1.0 equiv.), TSTU (1.0 equiv.), NMM (5.0 equiv.), (DMF) $23{ }^{\circ} \mathrm{C}, 15 \mathrm{~h}, 65 \%$ for 29 ; (e) 32 (1.0 equiv.), ( $\mathrm{MeCN}$ : PBS ( $\left.\mathrm{pH}=7.45\right) /$ $1: 2), 0{ }^{\circ} \mathrm{C}$ to $23^{\circ} \mathrm{C}, 2.5 \mathrm{~h}, 70 \%$ for 31 .

an $\alpha, \beta$-unsaturated ester. Based on results for an $\alpha, \delta$-unsaturated aldehyde derivative of anguinomycin $\mathrm{D}$ reported by Gademann and coworkers, ${ }^{67}$ such a species is presumed to retain bioactivity. All observed trends in activity, such as the relative decreases for 13 and 14 vs. 1, 17 vs. 16, or the absolute levels of activity of 18 and vs. 17 and 16, were much more<smiles>C/C=C/[C@H]1O[C@H](C(O)/C=C/C=C(\C)CC(C)/C=C(C)/C=C/[C@@H]2CC=CC(=O)O2)CC(N)C1C</smiles><smiles>C#CCCOC(=O)NC1CC([C@H](O)/C=C/C=C(\C)CC(C)/C=C(C)/C=C/[C@H]2CC=CC(=O)O2)O[C@H](/C=C/C)C1C</smiles><smiles>C#CCNC1C[C@H](C(O)C=CC=C(C)CC(C)C=C(C)C=CC2CC=CC(=O)O2)O[C@@H](C=CC)C1C</smiles>

Scheme 4 Semi-synthesis of alkyne-linked C16-aminoratjadones. Reagents and conditions: (a) $\mathrm{NH}_{4} \mathrm{OAc}$ (2.0 equiv.), $\mathrm{NaBH}_{3} \mathrm{CN}$ (2.0 equiv.), (MeOH), $23{ }^{\circ} \mathrm{C}, 4 \mathrm{~h}, 68 \%$ of 33 as $2: 1$-mixture of diastereomers; (b) 24 (1.1 equiv.), NMM (6.0 equiv.), $\left(\mathrm{CH}_{2} \mathrm{Cl}_{2}\right), 23^{\circ} \mathrm{C}, 20 \mathrm{~h}, 62 \%$ of 34 as a $2: 1$ mixture of diastereomers; (c) propargylamine (2.0 equiv.), $\mathrm{NaBH}_{3} \mathrm{CN}$ (2.0 equiv.), (MeOH), $23^{\circ} \mathrm{C}, 4 \mathrm{~h}, 99 \%$ of 35 as a $2: 1$-mixture of diastereomers.

pronounced for the murine fibroblast cell line L929 compared to the tested human cell lines (Table 1).

Short amide- or carbamate-linked terminal alkyne moieties at the $\mathrm{C} 16$ amino function as in 20, 21 and 22 were also tolerated, with $\mathrm{IC}_{50}$ values in the sub-nanomolar or single-digit nanomolar range. However, longer linkers such as the cathepsin B-cleavable citrulline-valine-pABA moiety (as in 25 and 26) or disulfidecontaining linkers (as in 29 and 31) at the C16 position led to

Table 1 Antiproliferative activity of novel aminoratjadone derivatives against a panel of cancer cell lines ${ }^{a}$

\begin{tabular}{lccccc}
\hline \multicolumn{5}{c}{ Antiproliferative activity $\mathrm{IC}_{50}[\mathrm{nM}]$} \\
\cline { 2 - 6 } & KB-3.1 & A-549 & SK-OV-3 & MCF-7 & L-929 \\
\hline $\mathbf{1}$ & 0.46 & 0.15 & 0.24 & 0.11 & 0.68 \\
$\mathbf{1 3}$ & 2.57 & 1.76 & 0.24 & 0.22 & 12.6 \\
$\mathbf{1 4}$ & 0.36 & 0.10 & 0.16 & 0.48 & 1.15 \\
$\mathbf{1 5}$ & 3.98 & 9.72 & 1.59 & 2.87 & 24.3 \\
$\mathbf{1 6}$ & 0.39 & 0.31 & 0.61 & 0.26 & 4.61 \\
$\mathbf{1 7}$ & 1.59 & 1.31 & 0.81 & 0.36 & 28.4 \\
$\mathbf{1 8}$ & 115.6 & - & - & - & 3307 \\
$\mathbf{1 9}$ & 165.4 & - & - & - & 1323 \\
$\mathbf{2 0}$ & 1.05 & 0.58 & 0.44 & 0.40 & - \\
$\mathbf{2 1}$ & 0.47 & 1.25 & 0.45 & 0.27 & 4.50 \\
$\mathbf{2 2}$ & 1.23 & 2.45 & 1.20 & 0.62 & - \\
$\mathbf{2 5}$ & 25.1 & 39.5 & 34.7 & 20.2 & - \\
$\mathbf{2 6}$ & 9.20 & 25.1 & 13.6 & 12.5 & - \\
$\mathbf{2 9}$ & 1.86 & 0.86 & 1.09 & 0.17 & - \\
$\mathbf{3 1}$ & 8.80 & 30.6 & 24.6 & 26.0 & - \\
$\mathbf{3 3}$ & 6.67 & 4.39 & 1.40 & 2.10 & - \\
$\mathbf{3 4}$ & 7.23 & 5.22 & 4.22 & 3.10 & - \\
$\mathbf{3 5}$ & 1.23 & 1.12 & 2.63 & 1.31 & -
\end{tabular}

${ }^{a}$ Cell line origin: KB-3.1: human cervix carcinoma, A-549: human lung carcinoma, SK-OV-3: human ovarian carcinoma, MCF: human breast carcinoma, L-929: murine fibroblast. 


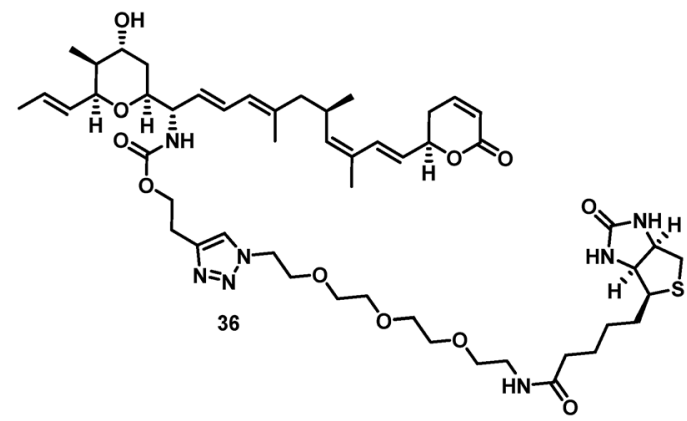

Fig. 3 Structure of biotin-PEG $3-16 S$-aminoratjadone conjugate 36 .

clear (up to 50-fold) drops in activity compared to 1. Furthermore, all 19-aminoratjadone derivatives were less active compared to the 16-aminoratjadones, but showed still potent $\mathrm{IC}_{50}$ values in the single digit nanomolar range.

Next, we investigated the nuclear export inhibitory activity of selected novel ratjadone derivatives with a fluorescent translocation biosensor system. ${ }^{77-79}$ This cellular assay uses HeLa cells that express a recombinant fusion protein consisting of a nuclear localization signal (SV40-NLS), glutathione Stransferase (GST), green fluorescent protein (GFP) and a nuclear export signal (HIV1-RevNES) (Fig. 2A). Due to the two transport signals (NLS/NES), the biosensor is permanently shuttling between nucleus and cytoplasm but resides predominantly in the cytoplasm due to a comparatively stronger NES in cancer cells. Export inhibiting compounds induce a nuclear accumulation of the GFP-signal (Fig. 2B). For all tested derivatives a potent nuclear export inhibitory activity could be demonstrated.

Notably, the aminoratjadones 16 and 17 displayed $\mathrm{IC}_{50}$ values comparable to the natural template (Fig. 2C and D).
The biotin- $\mathrm{PEG}_{3}-16 S$-aminoratjadone conjugate 36 (Fig. 3, for synthesis of $\mathbf{3 6}$ see ESI $\dagger$ ) had a nuclear export activity of $\mathrm{IC}_{50}$ $=152 \mathrm{nM}$. To verify that this activity was indeed CRM1mediated, HeLa cells were incubated with 36 at a concentration of $100 \mathrm{ng} \mathrm{mL} \mathrm{m}^{-1}$ for $5 \mathrm{~h}$ and lysed.

The cell lysate was incubated with streptavidin-coupled sepharose beads, and bound proteins were eluted, digested and identified by LC-MS/MS. The target CRM1 was clearly identified in this manner and strongly enriched compared to a control sample that was additionally incubated with an excess of 1.

The findings demonstrate that conjugates functionalized at the 16 position of 1 indeed bound to CRM1 and retained a nuclear export activity. We therefore assume that the cellular mechanism of $\mathbf{1}$ was not altered upon derivatization.

\section{Synthesis and biological evaluation of folate-based carrier molecules and fluorescein conjugates}

In order to probe whether ratjadones could serve as cytotoxic payloads for EDCs, they were conjugated to folate-based targeting moieties. In order to minimize uptake of the conjugates by passive diffusion, we incorporated polar amino acids as a hydrophilic spacer that were coupled to the $\gamma$-carboxylate of folate. For fast and simple bioorthogonal attachment to the effectors, we incorporated azide or sulfhydryl moieties to all carrier molecules.

The first azide-containing folate carrier molecules $\left(\mathrm{FA}-\mathrm{N}_{3}\right)$ were generated by a solution phase synthesis (Scheme 5). Starting from Fmoc-Lys(Boc)-OMe (37), the Fmoc cleavage in presence of piperidine and subsequent EDCI-mediated peptide coupling with Fmoc-Glu-OtBu led to formation of the dipeptide 38 in 58\% yield. The simultaneous acidic cleavage of the tertbutyl ester and Boc group in the presence of TFA, followed by

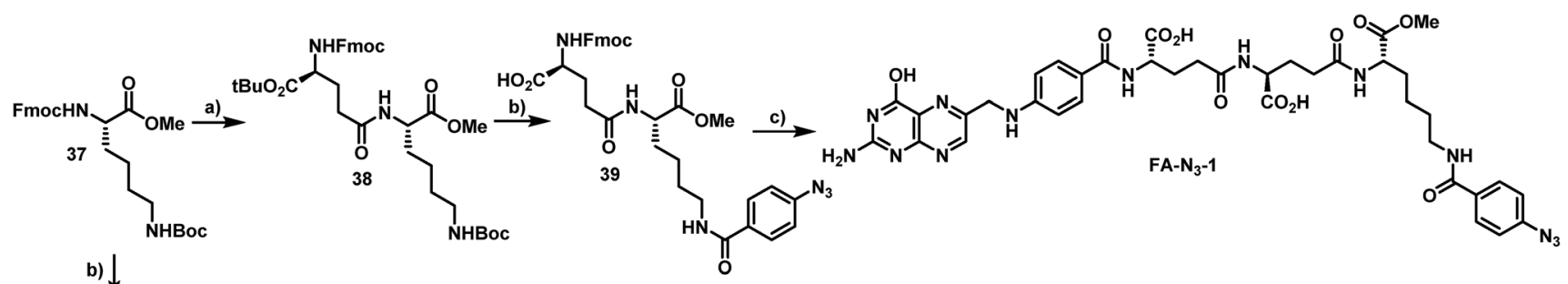

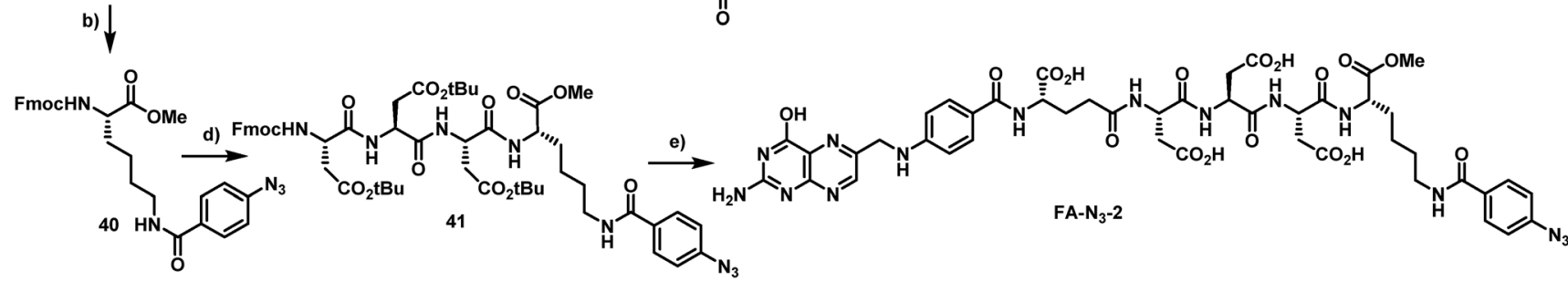

Scheme 5 Synthesis of azido-folate carrier molecules in solution. Reagents and conditions: (a) (1) Pip (xs), $\left(\mathrm{CH}_{2} \mathrm{Cl}_{2}\right), 23{ }^{\circ} \mathrm{C}, 3 \mathrm{~h},(2) \mathrm{Fmoc}-$ $(\text { Asp }(\mathrm{OtBu}))_{3}-\mathrm{OH}\left(1.2\right.$ equiv.), $\mathrm{EDCl} \mathrm{HCl}\left(1.1\right.$ equiv.), $\mathrm{HOAt}$ (1.1 equiv.), $\mathrm{NMM}\left(6.0\right.$ equiv.), (THF), $0^{\circ} \mathrm{C}+23^{\circ} \mathrm{C}, 24 \mathrm{~h}, 58 \%$ of 38 ; (b) (1) TFA (30 equiv.), $\left(\mathrm{CH}_{2} \mathrm{Cl}_{2}\right), 23^{\circ} \mathrm{C}, 22 \mathrm{~h}$, (2) $p$-azidobenzoic acid (1.1 equiv.), HATU (1.1 equiv.), HOAt (1.1 equiv.), NMM (10.0 equiv.), (DMF), $23^{\circ} \mathrm{C}, 24 \mathrm{~h}, 88 \%$ of 39 and $85 \%$ of 40 ; (c) (1) $\mathrm{Et}_{2} \mathrm{NH}$ (xs), (DMF), $23^{\circ} \mathrm{C}, 20 \mathrm{~h}$, (2) FA- $\gamma$-OSu (6.0 equiv.), NMM (6.0 equiv.), (DMSO), $23^{\circ} \mathrm{C}, 14 \mathrm{~h}, 48 \%$ of $\mathrm{FA}-\mathrm{N}_{3}-1 ;$; (d) (1) $\mathrm{Et}{ }_{2} \mathrm{NH}$ (xs), $\left(\mathrm{CH}_{2} \mathrm{Cl}_{2}\right), 23^{\circ} \mathrm{C}, 9 \mathrm{~h}$, (2) Fmoc-(Asp(OtBu) $)_{3}-\mathrm{OH}$ (1.2 equiv.). EDCI (1.2 equiv.), HOAt (1.2 equiv.), NMM (6.0 equiv.), (THF), 30 min preactivation at $23^{\circ} \mathrm{C}$, then $23^{\circ} \mathrm{C}, 5 \mathrm{~h}, 75 \%$ of 41 ; (e) (1) TFA (50 equiv.), $\left(\mathrm{CH}_{2} \mathrm{Cl}_{2}\right.$ ), $23^{\circ} \mathrm{C}, 20 \mathrm{~h}$, (2) Et ${ }_{2} \mathrm{NH}$ (xs), (DMF), $23^{\circ} \mathrm{C}, 20 \mathrm{~h},(3) \mathrm{FA}-\gamma-\mathrm{OSu}(6.0 \mathrm{equiv}$.), NMM (6.0 equiv.), (DMSO), $23^{\circ} \mathrm{C}, 16 \mathrm{~h}, 32 \%$ of $\mathrm{FA}-\mathrm{N}_{3}-2$. 
a HATU-mediated peptide coupling with $p$-azido benzoic acid, gave 39 in $88 \%$ yield.

Finally, the removal of the Fmoc group and subsequent conversion of the free amine with an excess of folic acid $\gamma-\mathrm{N}$ hydroxysuccinimide ester led to the formation of FA- $\mathbf{N}_{\mathbf{3}} \mathbf{- 1}$, which could be isolated in $48 \%$ yield. Starting from 37 , the Boc protective group was removed in the presence of TFA, and a HATU-mediated peptide coupling with $p$-azido benzoic acid yielded $\mathbf{4 0}$ in $85 \%$ yield. The removal of the Fmoc group and an EDCI-mediated peptide coupling with Fmoc-Asp( $t \mathrm{Bu})$-D$\operatorname{Asp}(t \mathrm{Bu})-\mathrm{Asp}(t \mathrm{Bu})-\mathrm{OH}$ tripeptide (synthesized on solid phase) led to formation of the tetrapeptide 41. The removal of tert-butyl esters and Fmoc and the subsequent conversion of the free amine with an excess of folic acid $\gamma$ - $N$-hydroxysuccinimide ester gave $\mathbf{F A - N} \mathbf{N}_{3}-2$ in $32 \%$ yield.

In order to avoid the methyl ester in the final folate carrier molecules and to provide a more convenient route to further folates, we developed a second route based on solid phasesupported peptide synthesis with 2-chlorotrityl resins. By applying standard HATU-mediated Fmoc peptide coupling chemistry and capping the resin-bound peptides with folic acid $\gamma$ - $N$-hydroxysuccinimide ester, the fully assembled folate carrier molecules were obtained in yields ranging from $20-61 \%$ after cleavage from the resin, global removal of the protective groups and purification by preparative HPLC. Following this procedure, nine additional azide-containing folate carrier molecules were generated, including $\mathbf{F A}-\mathbf{N}_{3} \mathbf{- 4}$ and $\mathbf{F A}-\mathbf{N}_{3} \mathbf{- 1 1}$ (Fig. 4), that were designed for a double or triple loading with aminoratjadones, respectively.

Lysine residues were introduced in $\mathbf{F A}-\mathbf{N}_{\mathbf{3}}-\mathbf{8}$ and $\mathbf{F A}-\mathbf{N}_{\mathbf{3}}-\mathbf{- 9}$ to reduce charge, while increasing hydrophilicity. Additionally, we synthesized FA-SH-1 as a literature-known example for a sulfhydryl-containing folate carrier molecule. ${ }^{80,81}$ We next synthesized fluorescein-labeled folate conjugates (FA-FITC) by coppermediated or metal-free azide-alkyne click chemistry with either the terminal-alkyne bearing 48 or the BCN-containing 49 (Fig. 4 and ESI $\dagger$ ).

The conjugates were then utilized to verify the ability of the folate carrier molecules to selectively deliver the fluorophore to KB-3.1 cancer cell lines, which express the folate receptor- $\alpha$ on their cell surface under folate-limiting media conditions. As exemplified for the folate-fluorescein conjugate FA-1-FITC (the click product of FA- $\mathbf{N}_{3}-\mathbf{1}$ and 43 , for exact structure see ESI $\dagger$ ), we observed a selective labelling of the FR $\alpha$-positive cell line KB3.1, while no fluorescent labelling was observed for the FR $\alpha$ negative cell line A-549 (Fig. 5A).

A significantly weaker fluorescence labelling occurred when free folic acid as a competitive binder for FR $\alpha$ was added to the cell medium, indicating a receptor-dependent labelling of the cells. This picture was similar for all folate-fluorescein conjugates tested.

Only with maximally enhanced brightness $(\mathrm{B}=\max )$, a low signal for FA-treated KB 3.1 cells was visible (Fig. 5A, inset).

A strong labelling was also observed at significantly lowered concentration of FA-1-FITC (70 nM, 5 min, see ESI Fig. S11†), and the signal persisted without visible decay over $72 \mathrm{~h}$ (Fig. 5B).<smiles>Nc1nc(O)c2nc(CNc3ccc(C(=O)NC(O)(O)CCC(=O)NCc4ccccc4)cc3)cnc2n1</smiles>
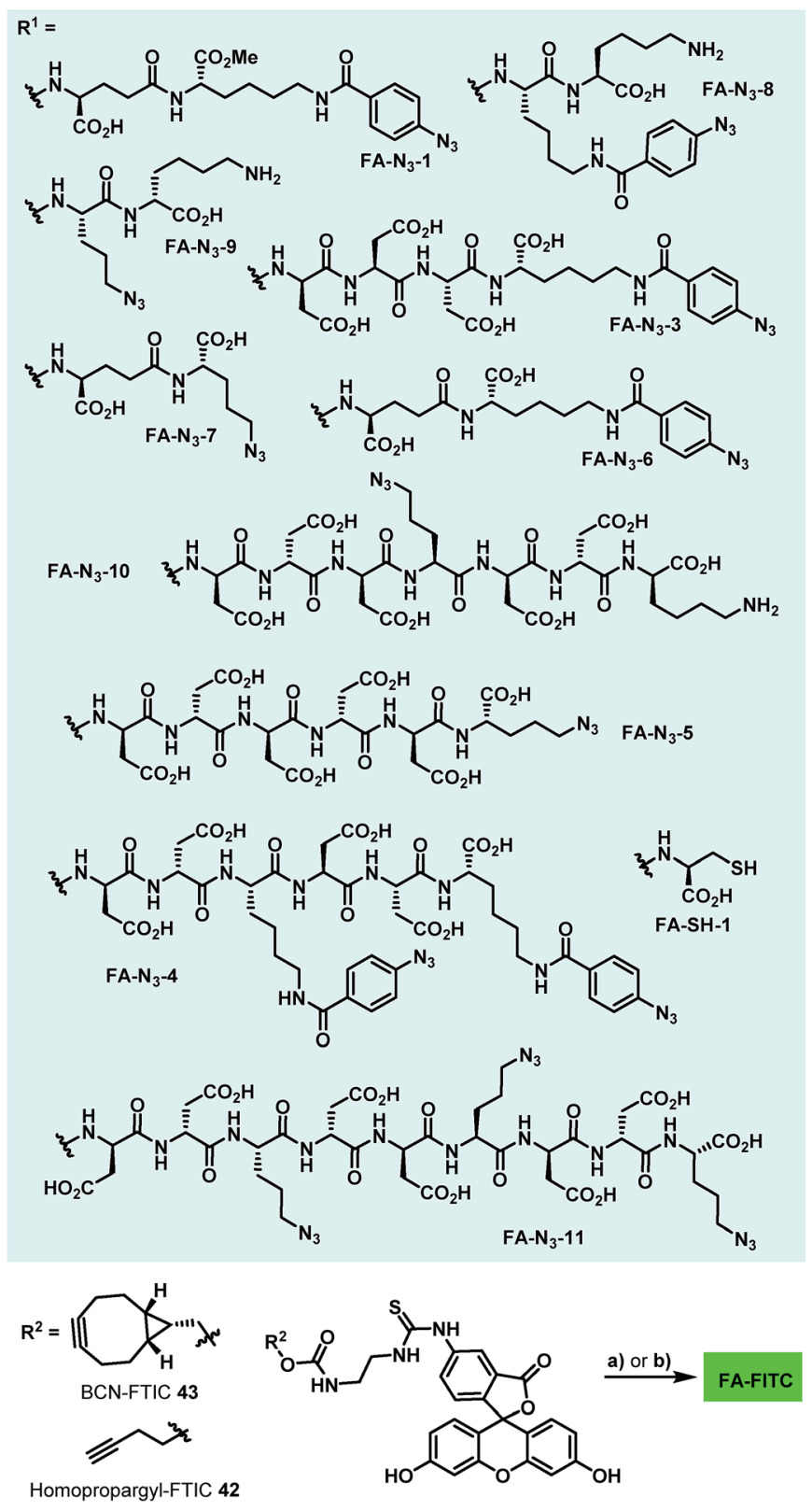

Fig. 4 Folate-based carrier molecules and folate-fluorescein conjugates synthesized in this study. Reagents and conditions: (a) FA- $\mathrm{N}_{3}$ (1.1 equiv.), $\mathrm{CuSO}_{4}$ (0.05 equiv.), TBTA (0.1 equiv.), NaAsc (0.5 equiv.), DiPEA (6.0 equiv.), (DMSO : $\left.\mathrm{H}_{2} \mathrm{O}:{ }^{t} \mathrm{BuOH} / 2: 1: 1\right), 23{ }^{\circ} \mathrm{C}, 2-24 \mathrm{~h}$; (b) $\mathrm{FA}-\mathrm{N}_{3}$ (1.1 equiv.), (DMSO), $23^{\circ} \mathrm{C}, 4-20 \mathrm{~h}$.

The fluorescence intensity per cell was quantified by flow cytometry of KB-3.1 cells that were treated with six folate-fluorescein conjugates. We observed similar mean fluorescence intensities per cell for most of the tested compounds, while free fluorescein did not label the cells (Fig. 6).

However, FA-4-FITC and FA-11-FITC, which are structurally based on the folate carrier molecules FA- $\mathrm{N}_{3}-4$ and FA- $\mathrm{N}_{3}-11$ and 
A
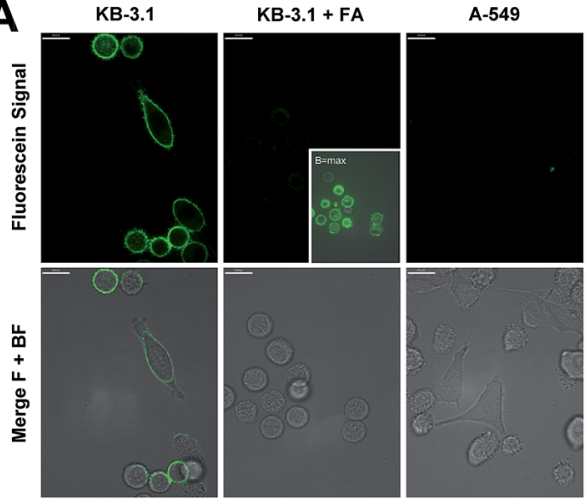

B
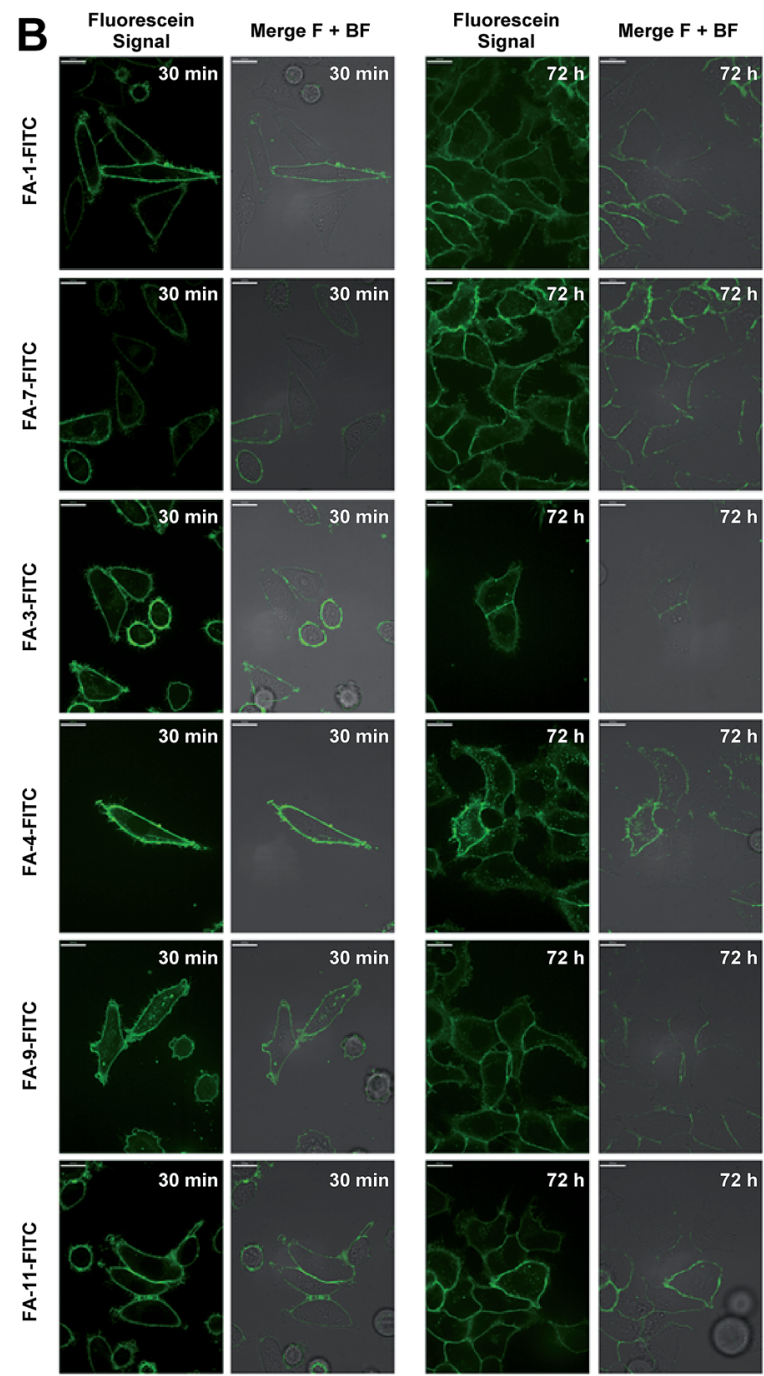

Fig. 5 Confocal fluorescence microscopy. (A) Imaging of KB 3.1 and A-549 cells with folate-fluorescein conjugate FA-1-FITC $(8.6 \mu \mathrm{M}$, $5 \mathrm{~min}, 37^{\circ} \mathrm{C}$ ). KB 3.1 cells were imaged in the presence (left) of absence (middle) of an excess of folic acid. (B) Imaging of KB 3.1 cells treated with $1 \mu \mathrm{M}$ of six folate-fluorescein conjugates at two different time points (30 $\mathrm{min}$ and $72 \mathrm{~h}$ ). All experiments were conducted in folatefree RPMI medium with $10 \%$ folate-containing FCS. Merge F + BF: merge fluorescence signal + bright field.

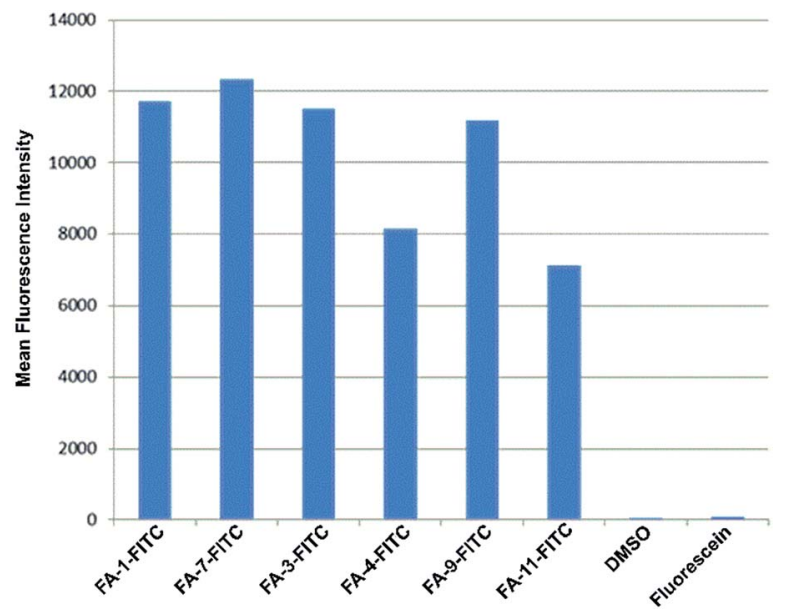

Fig. 6 Fluorescence intensity per cell determined by flow cytometry of KB 3.1 cells that were labelled with six different folate-fluorescein conjugates.

bear two or three fluorophore units, respectively, showed a reduced intensity compared to the other compounds.

\section{Synthesis and biological evaluation of folate-based ratjadone conjugates}

This might be due to an interference of the high fluorophore loading of the compounds with their binding to the receptor. None of the carriers showed any antiproliferative activity up to the highest concentration tested $(c a .10 \mu \mathrm{M})$ on KB-3.1 as well as A-549 cells, and the cells were completely viable (see ESI, Table S3†).

With appropriate folate carrier molecules in hand, we synthesized 11 novel folate-aminoratjadone conjugates bearing a cathepsin B-cleavable valine-citrulline- $p$ ABA unit (Fig. 7). The aminoratjadones 25 and 26 were coupled to different folate carrier molecules either with a metal-free azide-alkyne click reaction or with a copper(I)-mediated azide alkyne click reaction, respectively.

Additionally, 9 folate-aminoratjadone conjugates linked via short non-cleavable linkers were synthesized in presence of $\mathbf{2 1}$ or 35 (Fig. 7). Furthermore, reacting 31 with FA-SH-1 in an aqueous buffer system $(\mathrm{pH}=7.4)$ gave the FA-SS-16R-aminoratjadone, that contained a cleavable disulfide bridge (Fig. 7).

All folate-aminoratjadone conjugates were then evaluated for their antiproliferative activity against the folate receptorpositive cell line KB-3.1 and found to exhibit potent antiproliferative activity (Table 2). However, the conjugation was associated with a moderate loss of activity compared to the free aminoratjadones. This might be due to a reduced target affinity caused by steric interactions, in particular with the nearby helix $\mathrm{H} 12 \mathrm{~A}$ of CRM-1. ${ }^{55}$ In addition, the internalization efficiency of receptor-mediated, selective uptake might be reduced compared to the freely diffusing unconjugated molecules.

The most potent conjugate bearing a cleavable valinecitrulline- $p \mathrm{ABOH}$ linker was FA-7-Val-Cit-pABA-16R-aminoratjadone with an $\mathrm{IC}_{50}$ value of $34.3 \mathrm{nM}$. Surprisingly, FA-SS- 
<smiles>Nc1nc(O)c2nc(CNc3ccc(C(=O)NC(O)(CO)CCC(=O)O)cc3)cnc2n1</smiles><smiles>[Y]c1ccc(C(=O)NCCCCC(NC(=O)CC(CO)NC=[V])C(=O)O)cc1</smiles>

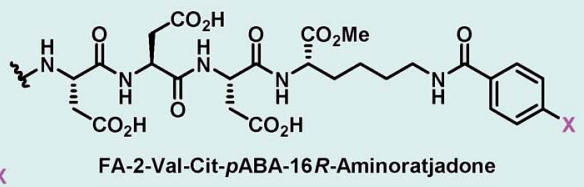
FA-1-Val-Cit-pABA-16R-Aminoratjadone

FA-2-Val-Cit-pABA-16R-Aminoratjadone
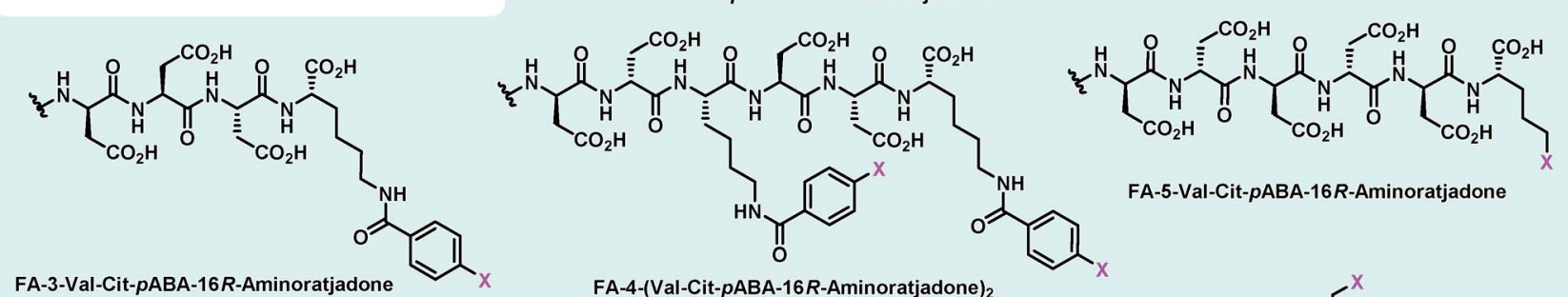

FA-6-Val-Cit-pABA-16R-Aminoratjadone

FA-4-(Val-Cit-pABA-16R-Aminoratjadone) $)_{2}$

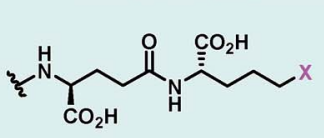

FA-7-Val-Cit-pABA-16R-Aminoratjadon

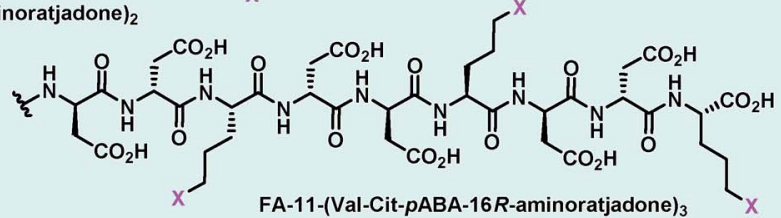

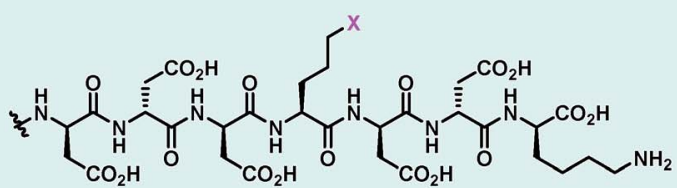

FA-10-Val-Cit-pABA-16R-Aminoratjadone<smiles>[X]CCC[C@H](NC)C(=O)N[C@@H](CCCCN)C(=O)O</smiles>

FA-9-Val-Cit-pABA-16R-Aminoratjadone
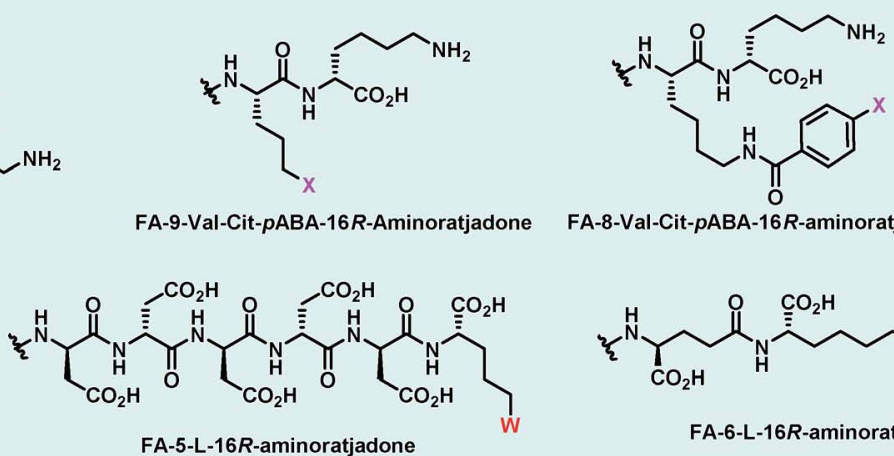

FA-8-Val-Cit-pABA-16R-aminoratjadone<smiles>C/C=C/C1O[C@@H]([C@H](/C=C/C=C(\C)CC(C)/C=C(C)/C=C/[C@H]2CC=CC(=O)O2)NC(=O)CCSSCC(NC)C(=O)O)C[C@@H](O)C1C</smiles><smiles>CCNC(CCCCNC(=O)c1ccc([N])cc1)C(=O)N[C@@H](CCCCN)C(=O)O</smiles><smiles>CNC(CCl)C(=O)O</smiles>

FA-8-L-16R-aminoratjadone

FA-5-L-16R-aminoratjadone

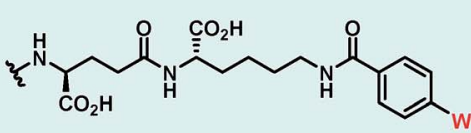

FA-6-L-16R-aminoratjadone

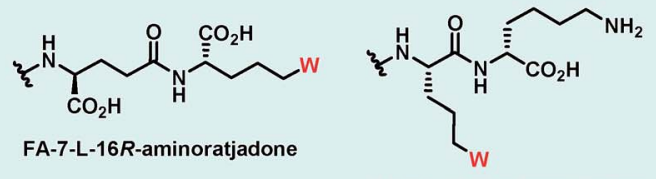

FA-9-L-16R-aminoratjadone

FA-10-L-16R-aminoratjadone

FA-3-L-16R-aminoratjadone $R^{2}=W$ $\begin{array}{ll}\text { FA-3b-L-16R-aminoratjadone } & R^{2}=Y \\ \text { FA-3-L-19-aminoratjadone } & R^{2}=Z\end{array}$

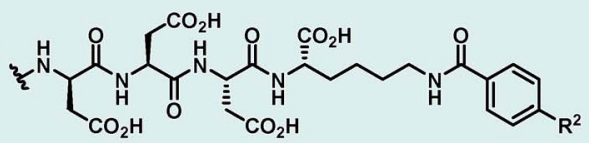

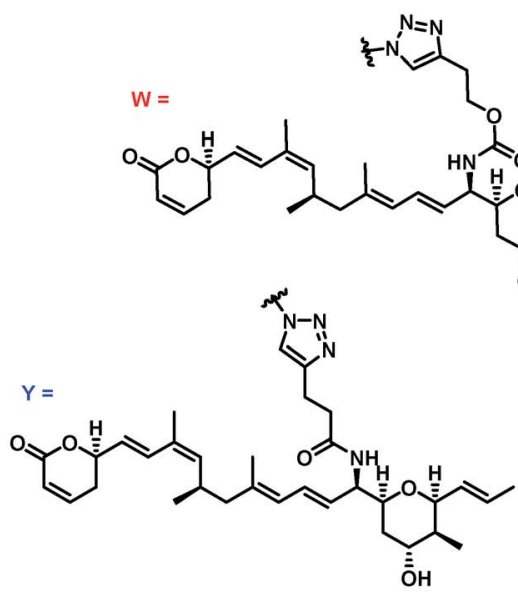

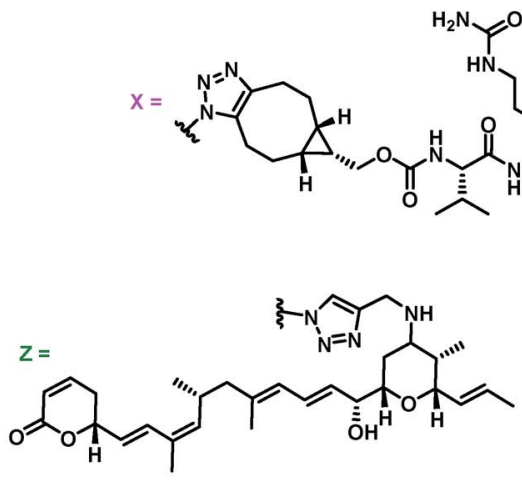<smiles>C/C=C/C1OC(C(/C=C/C=C(\C)CC(C)/C=C(C)/C=C/C2CC=CC(=O)O2)NC(=O)OCc2ccc(NC(=O)CC)cc2)C[C@@H](O)[C@@H]1C</smiles>

Fig. 7 Novel folate-aminoratjadone conjugates with non-cleavable and enzymatically cleavable linkers synthesized in this study. 
Table 2 Antiproliferative activity of novel folate-Ratjadone conjugates against KB-3.1 cancer cells

\begin{tabular}{|c|c|}
\hline Folate-ratjadone conjugate & $\mathrm{IC}_{50}[\mathrm{nM}]$ \\
\hline FA-1-Val-Cit-pABA-16R-aminoratjadone & 169 \\
\hline FA-2-Val-Cit-pABA-16R-aminoratjadone & 336 \\
\hline FA-3-Val-Cit-pABA-16R-aminoratjadone & 210 \\
\hline FA-4-(Val-Cit-pABA-16R-aminoratjadone $)_{2}$ & 148 \\
\hline FA-5-Val-Cit-pABA-16R-aminoratjadone & 237 \\
\hline FA-6-Val-Cit-pABA-16R-aminoratjadone & 223 \\
\hline FA-7-Val-Cit-pABA-16R-aminoratjadone & 34.3 \\
\hline FA-8-Val-Cit-pABA-16R-aminoratjadone & 39.9 \\
\hline FA-9-Val-Cit-pABA-16R-aminoratjadone & 50.9 \\
\hline FA-10-Val-Cit-pABA-16R-aminoratjadone & 35.3 \\
\hline FA-11-(Val-Cit-pABA-16R-aminoratjadone) $)_{3}$ & 45.0 \\
\hline FA-3-L-16R-aminoratjadone & 29.8 \\
\hline FA-3-L-19-aminoratjadone & 48.3 \\
\hline FA-3b-L-16R-aminoratjadone & 94.0 \\
\hline FA-5-L-16R-aminoratjadone & 50.3 \\
\hline FA-6-L-16R-aminoratjadone & 150 \\
\hline FA-7-L-16R-aminoratjadone & 190 \\
\hline FA-8-L-16R-aminoratjadone & 129 \\
\hline FA-9-L-16R-aminoratjadone & 47.6 \\
\hline FA-10-L-16R-aminoratjadone & 708 \\
\hline FA-SS-16R-aminoratjadone & 295 \\
\hline
\end{tabular}

16R-amino-ratjadone bearing a disulfide linker showed a significant drop in antiproliferative activity ( $\mathrm{IC}_{50}$ of $295 \mathrm{nM}$ ). This might be due to an inactivation of the drug's warhead by a 1,4-conjugate addition of the released sulfhydryl residue upon cleavage. Obviously, the cathepsin B-specific cleavage site of the conjugates was not essential for a high antiproliferative activity, because several conjugates bearing short, non-cleavable linkers were comparably active; FA-3-L-16R-aminoratjadone with an $\mathrm{IC}_{50}$ of $29.8 \mathrm{nM}$ was even the most potent conjugate in the series. However, we cannot exclude that the hydrophilic peptide spacer in the folate carrier molecules gets (partially) hydrolyzed in the lysosomal compartment after endocytotic uptake. The comparable potency of 19-aminoratjadones and 16-aminoratjadones reported above was also found for the full conjugates, as FA-3-L-19-aminoratjadone showed an $\mathrm{IC}_{50}$ value of $48.3 \mathrm{nM}$. The spread in potency between the most potent and the weakest compound was about 20-fold, which underlines the crucial importance of the linker and the need to study a broader set of linkers. We observed that longer linkers were disfavored in the cleavable Val-Cit series (compare FA-5-Val-Cit-pABA-16Raminoratjadone $v s$. FA-7-Val-Cit-pABA-16R-aminoratjadone). However, other parameters like the net charge of the linker, aryl-azide $v s$. alkyl-azide attachment chemistry, or the number of payloads did not have an obvious positive or negative impact on SAR.

\section{Synthesis and biological evaluation of LHRH-based ratjadone conjugates}

Encouraged by the results from the folate conjugates, we wanted to demonstrate the general applicability of ratjadone payloads by using a second targeting moiety. Luteinizing hormone releasing hormone (LHRH)-based carriers were selected for this purpose, because it has been shown that several cancer cell types overexpress receptors for LHRH, a peptidehormone involved in regulation of the sex glands of males and females. ${ }^{25,26,29,82-84}$ We synthesized three novel derivatives of LHRH that bear azido-ornithine as fifth amino acid of the decapeptide core structure instead of the glycine residue found in the natural peptide (Fig. 8). As the importance of the newly introduced stereocenter was unclear, both diastereoisomers $\mathbf{L}^{-}$ Orn- $\mathbf{N}_{\mathbf{3}}$-LHRH and D-Orn-N $\mathbf{N}_{\mathbf{3}}$-LHRH were prepared. An additional analog, D-Orn- $\mathbf{N}_{3}$-Gose, was based on the synthetic LHRH analogue goserelin, that was reported to have higher affinity for the LHRH-receptor ${ }^{85}$ due to a hydrazine carboxamide in the C-

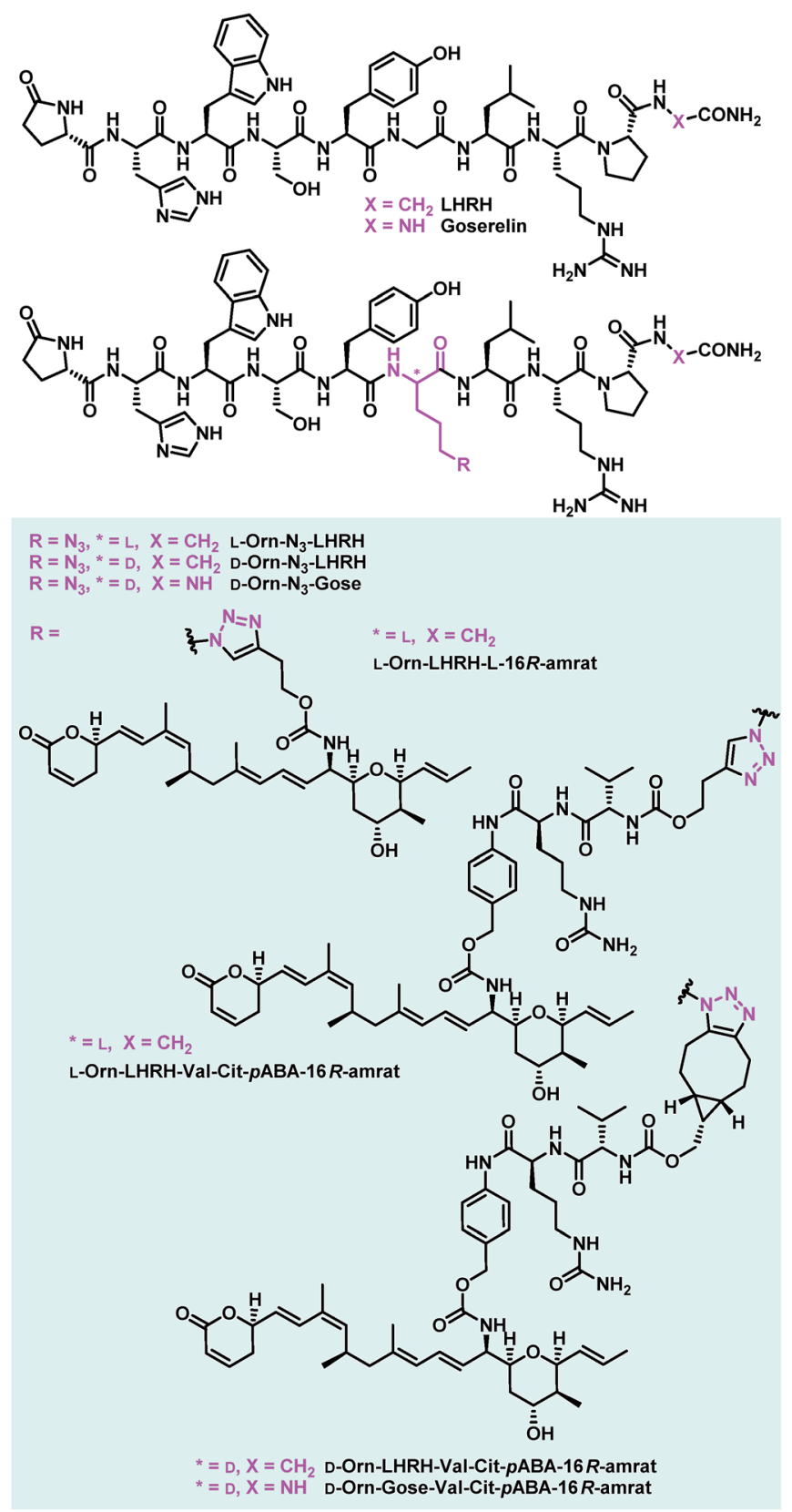

Fig. 8 Novel LHRH derivatives and LHRH-aminoratjadone conjugates synthesized in this study. 

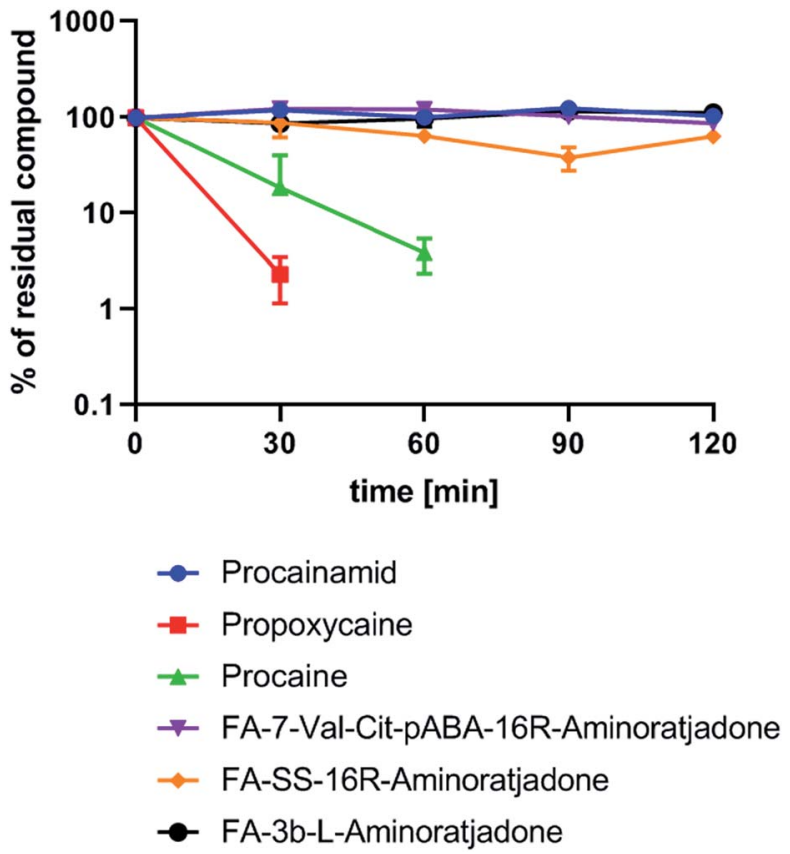

Fig. 9 Human plasma stability of selected folate-aminoratjadone conjugates and reference compounds $\left(10 \mu \mathrm{g} \mathrm{mL}^{-1}\right.$ in human plasma at $37^{\circ} \mathrm{C}$ and $\mathrm{pH}=7.4$ )

terminal position. The compounds were synthesized using TBTU-mediated solid phase-supported peptide coupling on a Rink amide resin. Next, their antiproliferative activities were evaluated in a panel of cancer cell lines, in order to assess a contribution of the drug-free targeting moiety to bioactivity. While LHRH, L-Orn- $\mathbf{N}_{3}$-LHRH and D-Orn- $\mathbf{N}_{3}$-Gose had no antiproliferative activity, we were surprised to find that $\mathbf{D}-\mathbf{O r n}-\mathbf{N}_{\mathbf{3}^{-}}$LHRH displayed moderate activities against KB-3.1, A-549, SKOV-3 and a high ( $\mathrm{IC}_{50}$ of $47.4 \mathrm{nM}$ ) activity against MCF-7 (Table 3 and ESI, Table S3†). To obtain full LHRHaminoratjadone conjugates, $\mathbf{2 1}, \mathbf{2 5}$ or $\mathbf{2 6}$ were coupled to the LHRH analogs under metal-free or copper-mediated azidealkyne click conditions (Fig. 9). The conjugates were evaluated for their antiproliferative activity against the LHRH-receptorpositive lung cancer cell line A-549 (Table 3). Cleavable and non-cleavable conjugates based on $\mathbf{L}$-Orn- $\mathbf{N}_{\mathbf{3}}$-LHRH as carrier molecule showed only moderate antiproliferative activity, but $\mathbf{D}^{-}$ Orn-LHRH-Val-Cit-pABA-16R-aminoratjadone and D-Orn-GoseVal-Cit-pABA-16R-aminoratjadone were highly potent with $\mathrm{IC}_{50}$ values of $23.0 \mathrm{nM}$ and $12.8 \mathrm{nM}$, respectively. While

Table 3 Antiproliferative activities of LHRH-ratjadone conjugates and D-Orn- $\mathrm{N}_{3}-\mathrm{LHRH}$ against the $\mathrm{LHRH}$-receptor-positive cancer cell line A-549

LHRH-ratjadone conjugate

L-Orn-N $\mathbf{N}_{3}$-LHRH

L-Orn-LHRH-16R-aminoratjadone

L-Orn-LHRH-Val-Cit-pABA-16R-aminoratjadone

D-Orn-LHRH-Val-Cit-pABA-16R-aminoratjadone

D-Orn-Gose-Val-Cit-pABA-16R-aminoratjadone
$\mathrm{IC}_{50}[\mathrm{nM}]$ a contribution of the carrier to bioactivity cannot be excluded for D-Orn-LHRH-Val-Cit-pABA-16R-aminoratjadone, the effect of the latter compound is ascribed to the ratjadone payload. In fact, D-Orn-Gose-Val-Cit-pABA-16R-aminoratjadone represents the most active aminoratjadone conjugate synthesized in this study.

Finally, a first experiment to assess whether aminoratjadone conjugates are sufficiently stable for in vivo applications was conducted, given that the amide and carbamate groups in the molecules are potentially labile.

We exposed three selected conjugates, FA-7-Val-Cit-PABA16R-aminoratjadone, FA-SS-16R-aminoratjadone and FA-3b16R-aminoratjadone, to human plasma and quantified their relative amount at different time points by HPLC-MS/MS analysis (Fig. 9).

Three reference compounds were included in the set: whereas procain as well as propoxycain are known to degrade rapidly in plasma, procainamide is stable. ${ }^{86}$ Fortunately, all tested conjugates were found to be stable over a period of two hours, whereas the positive controls procain and propoxycain were degraded by more than $90 \%$. Since receptor binding of comparable conjugates normally occurs within $<15$ minutes after intravenous administration, ${ }^{87,88}$ and clearance from the blood stream is $>99 \%$ completed after 20 minutes, ${ }^{87,89}$ a stability over two hours is considered as being sufficient for in vivo applications.

\section{Conclusions}

In order to establish nuclear export inhibition as a novel effector principle for extracellular-targeted cancer therapies, we have conjugated the highly potent CRM-1 inhibitor ratjadone A to small molecule targeting ligands. A semi-synthesis program with gram quantities of the natural product led to a reliable access to novel 16- and 19-aminoratjadone derivatives. The compounds fully retained the potent antiproliferative activity and target selectivity of the free natural product at increased water solubility. The ability of aminoratjadones to serve as cytotoxic payloads was addressed by the synthesis and characterization of a series of folate- and LHRH-based EDCs with a broad variety of linkers harboring different cleavage mechanisms. The selective targeting of receptor-positive cells was demonstrated by confocal imaging of fluorescein conjugates. Moreover, aminoratjadon-loaded EDC's showed potent antiproliferative activities against receptor-positive cancer cell lines in the double-digit nM range (e.g. FA-7-Val-Cit-pABA-16R-aminoratjadone $\left(\mathrm{IC}_{50}=34.3 \mathrm{nM}\right)$, FA-3-L-16R-aminoratjadone $\left(\mathrm{IC}_{50}=29.8 \mathrm{nM}\right)$, or $\mathbf{D}$-Orn-Gose-Val-Cit-pABA-16R-aminoratjadone $\left(\mathrm{IC}_{50}=12.8 \mathrm{nM}\right)$ ). A complete profiling of the conjugates in a large cell line panel of varying degrees of folate receptor expression to assess the conjugate's selectivity will be performed in future studies. As the conjugates are stable in human plasma, they appear suited to enter an in vivo proof-ofconcept in animals. Furthermore, the clickable ratjadone-linker modules can be readily conjugated to other targeting formats like antibodies or aptamers, thereby opening interesting extended applications of the aminoratjadone effector platform. 


\section{Author contributions}

The research was planned and the manuscript was written by P. K. and M. B.. P. K. synthesized all new ratjadone derivatives, linkers, drug-conjugates and fluorophore-conjugates. A. R. and T. A. contributed to the isolation of the natural product and supported in the synthesis of linkers and conjugates. V. F. planned and executed CRM1 activity assays of ratjadone derivatives. V. F. did fluorescence microscopy and flowcytometry of fluorophore-conjugates. V. F. carried out biotinratjadone pulldown experiments. W. C. and B. H. carried out cytotoxicity assays of compounds. W. T. performed the solid-supported synthesis of LHRH derivatives. K. R. carried out plasma stability tests on drug-conjugates. S. H. and K. I. M. carried out the fermentation of Sorangium cellulosum. J. W. and L. J. identified proteins from Biotin-Ratjadone pulldown experiments.

\section{Conflicts of interest}

Parts of this work is part of a (so far unpublished) patent application: new targeted cytotoxic ratjadone derivatives and conjugates thereof, P. Klahn, M. Brönstrup, V. Fetz, S. Hüttel, K. I. Mohr, W. Tegge and W. Collisi, 2017, EP2017 185598.4 (Eur. Patent, Submission: 09.08.2017).

\section{Acknowledgements}

P. K. thanks the Alexander-von-Humboldt Foundation for a Feodor-Lynen Fellowship. The authors thank Janine Schreiber and Brigitte Kornak for experimental support and Ulrike Beutling, Heike Overwin and Christel Kakoschke for analytical support. The authors thank Dr Raimo Franke, Dr Giambattista Testolin and Dr Kevin Ferreira for helpful discussions.

\section{Notes and references}

1 G. Casi and D. Neri, J. Controlled Release, 2012, 161, 422-428.

2 F. Dosio, B. Stella, S. Cerioni, D. Gastaldi and S. Arpicco, Recent Pat. Anti-Cancer Drug Discov., 2014, 9, 35-65.

3 S. Panowski, S. Bhakta, H. Raab, P. Polakis and J. R. Junutula, $m A b s, 2014,6,34-45$.

4 R. V. J. Chari, M. L. Miller and W. C. Widdison, Angew. Chem., Int. Ed., 2014, 53, 3796-3827.

5 A. Thomas, B. A. Teicher and R. Hassan, Lancet Oncol., 2016, 17, e254-e262.

6 Y. Wang, A. G. Cheetham, G. Angacian, H. Su, L. Xie and H. Cui, Adv. Drug Delivery Rev., 2017, 110, 112-126.

7 B. Narasimhan, J. T. Goodman and J. E. Vela Ramirez, Annu. Rev. Biomed. Eng., 2016, 18, 25-49.

8 I. Vergote and C. P. Leamon, Ther. Adv. Med. Oncol., 2015, 7, 206-218.

9 P. Polakis, Pharmacol. Rev., 2016, 68, 3-19.

$10 \mathrm{H}$. Bouchard, C. Viskov and C. Garcia-echeverria, Bioorg. Med. Chem. Lett., 2014, 24, 5357-5363.

11 N. Krall, J. Scheuermann and D. Neri, Angew. Chem., Int. Ed., 2013, 52, 1384-1402.
12 L. R. Desnoyers, O. Vasiljeva, J. H. Richardson, A. Yang, E. E. M. Menendez, T. W. Liang, C. Wong, P. H. Bessette, K. Kamath, S. J. Moore, J. G. Sagert, D. R. Hostetter, F. Han, J. Gee, J. Flandez, K. Markham, M. Nguyen, M. Krimm, K. R. Wong, S. Liu, P. S. Daugherty, J. W. West and H. B. Lowman, Sci. Transl. Med., 2013, 5, 207 ra144.

13 A. M. Hohlbaum and A. Skerra, Expert Rev. Clin. Immunol., 2007, 3, 491-501.

14 M. Gebauer and A. Skerra, Anticalins: Small engineered binding proteins based on the lipocalin scaffold, Elsevier Inc., 1st edn, 2012, vol. 503.

15 A. Skerra, Rev. Mol. Biotechnol., 2001, 74, 257-275.

16 F. Kratz, P. Senter and H. Steinhagen, Drug Delivery in Oncology: From Basic Research to Cancer Therapy, Wiley, 2011.

17 I. R. Vlahov and C. P. Leamon, Bioconjugate Chem., 2012, 23, 1357-1369.

18 J. A. Reddy, R. Dorton, E. Westrick, A. Dawson, T. Smith, L. C. Xu, M. Vetzel, P. Kleindl, I. R. Vlahov and C. P. Leamon, Cancer Res., 2007, 67, 4434-4442.

19 C. P. Leamon and P. S. Low, Drug Discovery Today, 2001, 6, 44-51.

20 P. S. Low and S. A. Kularatne, Curr. Opin. Chem. Biol., 2009, 13, 256-262.

21 H. Shen, D. Hu, J. Du, X. Wang, Y. Liu, Y. Wang, J. min Wei, D. Ma, P. Wang and L. Li, Eur. J. Pharmacol., 2008, 601, 2329.

22 R. Jaskula-Sztul, Y. Xiao, A. Javadi, J. Eide, W. Xu, M. Kunnimalaiyaan, H. Chen and S. Gong, Cancer Res., 2012, 4, 7185-7193.

23 X. Qi, Y. Chen, N. Ma, Z. Zhang, J. Xing, X. Zhu, Z. Li and Z. Wu, J. Drug Targeting, 2014, 22, 428-438.

24 M. Lelle, S. Kaloyanova, C. Freidel, M. Theodoropoulou, M. Musheev, C. Niehrs, G. Stalla and K. Peneva, Mol. Pharm., 2015, 12, 4290-4300.

25 O. Argyros, T. Karampelas, X. Asvos, A. Varela, N. Sayyad, A. Papakyriakou, C. H. Davos, A. G. Tzakos, D. Fokas and C. Tamvakopoulos, Cancer Res., 2016, 76, 1181-1192.

26 J. Engel, G. Emons, J. Pinski and A. V Schally, Expert Opin. Invest. Drugs, 2012, 21, 891-899.

27 D. Wen, D. Chitkara, H. Wu, M. Danquah, R. Patil, D. D. Miller and R. I. Mahato, Pharm. Res., 2014, 31, 27842795.

28 C. Yates, S. Sharp, J. Jones, D. Topps, M. Coleman, R. Aneja, J. Jaynes and T. Turner, Biochem. Pharmacol., 2011, 81, 104110.

29 H. M. Vishwasrao, A. M. Master, Y. G. Seo, X. M. Liu, N. Pothayee, Z. Zhou, D. Yuan, M. D. Boska, T. K. Bronich, R. M. Davis, J. S. Riffle, M. Sokolsky-Papkov and A. V. Kabanov, Chem. Mater., 2016, 28, 3024-3040.

30 Y. Gilad, M. Firer and G. Gellerman, Biomedicines, 2016, 4, 124.

31 Y. Lu and P. S. Low, Adv. Drug Delivery Rev., 2012, 64, 342352.

32 P. S. Low, W. A. Henne and D. D. Doorneweerd, Acc. Chem. Res., 2008, 41, 120-129.

33 G. M. van Dam, G. Themelis, L. M. Crane, N. J. Harlaar, R. G. Pleijhuis, W. Kelder, A. Sarantopoulos, J. S. de Jong, 
H. J. G. Arts, A. G. J. van der Zee, J. Bart, P. S. Low and V. Ntziachristos, Nat. Med., 2011, 17, 1315-1319.

34 O. T. Okusanya, E. M. Dejesus, J. X. Jiang, R. P. Judy, O. G. Venegas, C. G. Deshpande, D. F. Heitjan, S. Nie, P. S. Low and S. Singhal, J. Thorac. Cardiovasc. Surg., 2015, 150, 28-35.

35 K. C. Nicolaou, J. Yin, D. Mandal, R. D. Erande, P. Klahn, M. Jin, M. Aujay, J. Sandoval, J. Gavrilyuk and D. Vourloumis, J. Am. Chem. Soc., 2016, 138, 1698-1708.

36 J. R. McCombs and S. C. Owen, AAPS J., 2015, 17, 339-351.

37 A. Beck, L. Goetsch, C. Dumontet and N. Corvaïa, Nat. Rev. Drug Discovery, 2017, 16, 315-337.

38 C. A. Leverett, S. C. K. Sukuru, B. C. Vetelino, S. Musto, K. Parris, J. Pandit, F. Loganzo, A. H. Varghese, G. Bai, B. Liu, D. Liu, S. Hudson, V. R. Doppalapudi, J. Stock, C. J. O'Donnell and C. Subramanyam, ACS Med. Chem. Lett., 2016, 7, 999-1004.

39 J. M. Lambert and C. Q. Morris, Adv. Thermoelectr., 2017, 34, 1015-1035.

40 C. Wayua, J. Roy, K. S. Putt and P. S. Low, Mol. Pharm., 2015, 12, 2477-2483.

41 K. C. Nicolaou, R. D. Erande, J. Yin, D. Vourloumis, M. Aujay, J. Sandoval, S. Munneke and J. Gavrilyuk, J. Am. Chem. Soc., 2018, 140, 3690-3711.

42 J. Mantaj, P. J. M. Jackson, K. M. Rahman and D. E. Thurston, Angew. Chem., Int. Ed., 2017, 56, 462-488.

43 T. Hechler, M. Kulke and J. Anderl, in Optimizing AntibodyDrug Conjugates for Targeted Delivery of Therapeutics, ed. N. Sewald, Future Science FSG, 2015, pp. 22-38.

44 S. Puthenveetil, F. Loganzo, H. He, K. Dirico, M. Green, J. Teske, S. Musto, T. Clark, B. Rago, F. Koehn, R. Veneziale, H. Falahaptisheh, X. Han, F. Barletta, J. Lucas, C. Subramanyam, C. J. O'Donnell, L. N. Tumey, P. Sapra, H. P. Gerber, D. Ma and E. I. Graziani, Bioconjugate Chem., 2016, 27, 1880-1888.

45 M. Kleppe and R. L. Levine, Nat. Med., 2014, 20, 342-344.

46 F. Michor and K. Polyak, Cancer Prev. Res., 2010, 3, 13611364.

47 M. R. Junttila and F. J. de Sauvage, Nature, 2013, 501, 346354.

48 J. P. B. O'Connor, Semin. Cell Dev. Biol., 2016, 1-10.

49 A. Persidis, Nat. Biotechnol., 1999, 17, 94-95.

50 G. Housman, S. Byler, S. Heerboth, K. Lapinska, M. Longacre, N. Snyder and S. Sarkar, Cancers, 2014, 6, 1769-1792.

51 D. Schummer, K. Gerth, H. Reichenbach and G. Höfle, Liebigs Ann., 1995, 685-688.

52 K. Gerth, D. Schummer, G. Höfle, H. Irschik and H. Reichenbach, J. Antibiot., 1995, 48, 973-976.

53 M. Kalesse and M. Christmann, Synthesis, 2002, 9811003.

54 M. Köster, S. Lykke-Andersen, Y. A. Elnakady, K. Gerth, P. Washausen, G. Höfle, F. Sasse, J. Kjems and H. Hauser, Exp. Cell Res., 2003, 286, 321-331.

55 Q. Sun, Y. P. Carrasco, Y. Hu, X. Guo, H. Mirzaei, J. Macmillan and Y. M. Chook, Proc. Natl. Acad. Sci. U. S. A., 2013, 110, 1303-1308.
56 G. Rabut, V. Doye and J. Ellenberg, Nat. Cell Biol., 2004, 6, 1114-1121.

57 K. Weis, Cell, 2003, 112, 441-451.

58 J. G. Turner, J. Dawson and D. M. Sullivan, Biochem. Pharmacol., 2012, 83, 1021-1032.

59 Q. Sun, X. Chen, Q. Zhou, E. Burstein, S. Yang and D. Jia, Signal Transduction Targeted Ther., 2016, 1, 16010.

60 J. G. Turner, J. Dawson, C. L. Cubitt, R. Baz and D. M. Sullivan, Semin. Cancer Biol., 2014, 27, 62-73.

61 M. El-Tanani, E. H. Dakir, B. Raynor and R. Morgan, Cancers, 2016, 8, 1-11.

62 E. S. Newlands, G. J. S. Rustin and M. H. Brampton, Br. J. Cancer, 1996, 74, 648-649.

63 U. Bhatt, M. Christmann, M. Quitschalle, E. Claus and M. Kalesse, J. Org. Chem., 2001, 66, 1885-1893.

64 M. Kalesse, M. Christmann, U. Bhatt, M. Quitschalle, E. Claus, A. Saeed, A. Burzlaff, C. Kasper, L. O. Haustedt, E. Hofer, T. Scheper and W. Beil, ChemBioChem, 2001, 2, 709-714.

65 W. Beil, U. Bhatt, A. Burzlaff, K. Chary, M. Christmann, E. Claus, M. Kalesse, C. Kasper, M. Quitschalle and T. Scheper, EP2002/1383764 A0, 2002.

66 A. Burzlaff, C. Kasper, T. Scheper, M. Kalesse, U. Bhatt, K. Chary, C. Eckhard, M. Christmann, M. Quitschalle and W. Beil, US2004/0092581 A1, 2004.

67 S. Bonazzi, O. Eidam, S. Güttinger, J. Y. Wach, I. Zemp, U. Kutay and K. Gademann, J. Am. Chem. Soc., 2010, 132, 1432-1442.

68 E. A. Crane and K. Gademann, Angew. Chem., Int. Ed., 2016, 55, 3882-3902.

69 M. Frigerio, M. Santagostino and S. Sputore, J. Org. Chem., 1999, 64, 4537-4538.

70 T. R. Hoye and M. K. Renner, J. Org. Chem., 1996, 7, 84898495.

71 J. A. Dale, D. L. Dull and H. Mosher, J. Org. Chem., 1969, 34, 2543-2549.

72 D. A. Allen, A. E. Tomaso, O. P. Priest and W. S. Colleges, J. Chem. Educ., 2008, 85, 698-700.

73 G. M. Dubowchik, R. A. Firestone, L. Padilla, D. Willner, S. J. Hofstead, K. Mosure, J. O. Knipe, S. J. Lasch and P. A. Trail, Bioconjugate Chem., 2002, 13, 855-869.

74 S. O. Doronina, T. D. Bovee, W. D. Meyer, J. B. Miyamoto, M. E. Anderson, C. A. Morris-Tilden and P. D. Senter, Bioconjugate Chem., 2008, 19, 1960-1963.

75 M. Dorywalska, R. Dushin, L. Moine, S. E. Farias, D. Zhou, T. Navaratnam, V. Lui, A. Hasa-Moreno, M. Galindo Casas, T.-T. Tran, K. Delaria, S.-H. Liu, D. Foletti, C. J. O'Donnell, J. Pons, D. L. Shelton, A. Rajpal and P. Strop, Mol. Cancer Ther., 2016, 15, 1-14.

76 F. L. Van Delft, R. Van Geel and M. A. Wijdeven, WO2014/ 065661 A1, 2014.

77 S. K. Knauer and R. H. Stauber, Anal. Chem., 2005, 77, 48154820 .

78 S. K. Knauer, S. Moodt, T. Berg, U. Liebel, R. Pepperkok and R. H. Stauber, Traffic, 2005, 6, 594-606.

79 V. Fetz, S. K. Knauer, C. Bier, J. P. von Kries and R. H. Stauber, Sensors, 2009, 9, 5423-5445. 
80 F. Taft, K. Harmrolfs, I. Nickeleit, A. Heutling, M. Kiene, N. Malek, F. Sasse and A. Kirschning, Chem.-Eur. J., 2012, 18, 880-886.

81 K. Harmrolfs, L. Mancuso, B. Drung, F. Sasse and A. Kirschning, Beilstein J. Org. Chem., 2014, 10, 535-543.

82 G. Emons, H. Sindermann, J. Engel, A. V. Schally and C. Gründker, Neuroendocrinology, 2009, 90, 15-18.

83 S. Seitz, S. Buchholz, A. V. Schally, F. Weber, M. Klinkhammer-Schalke, E. C. Inwald, R. Perez, F. G. Rick, L. Szalontay, F. Hohla, S. Segerer, C. W. Kwok, O. Ortmann and J. B. Engel, BMC Cancer, 2014, 14, 847.
84 D. Böhme and A. G. Beck-Sickinger, J. Pept. Sci., 2015, 21, 186-200.

85 C. M. Perry and R. N. Brogden, Drugs, 1996, 51, 319-346.

86 D. A. Hartmann, Curr. Protoc. Pharmacol., 2002, 19, 7.6.17.6.8.

87 W. Xia and P. S. Low, J. Med. Chem., 2010, 53, 6811-6824.

88 E. Vlashi, J. E. Sturgis, M. Thomas and P. S. Low, Mol. Pharm., 2009, 6, 1868-1875.

89 J. Li, E. A. Sausville, P. J. Klein, D. Morgenstern, C. P. Leamon, R. A. Messmann and P. LoRusso, J. Clin. Pharmacol., 2009, 49, 1467-1476. 